\begin{tabular}{lllllllllll} 
O P E R A T I O N S R E S E A R C H A N D D E C I S I O N S \\
\hline
\end{tabular}

No. 2

DOI: $10.37190 /$ ord 210203

\title{
CONTAGION EFFECTS ON CAPITAL AND FOREX MARKETS AROUND GFC AND COVID-19 CRISES. A COMPARATIVE STUDY
}

\author{
KRZYSZTOF BRANIA*, HENRYK GURGUL \\ Department of Applications of Mathematics in Economics, Faculty of Management, \\ AGH University of Science and Technology, 30-067 Krakow, Poland
}

\begin{abstract}
The spread of crises across the financial and capital markets of different countries has been studied. The standard method of contagion detection is based on the evolution of the correlation matrix for the example of exchange rates or returns, usually after removing univariate dynamics with the GARCH model. It is a common observation that crises that have occurred in one financial market are usually transmitted to other financial markets/countries simultaneously and that they are visible in different financial variables such as returns and volatility which determine probability distribution. The changes in distributions can be detected through changes in the descriptive statistics of, e.g., returns characterised by expected value, variance, skewness, kurtosis, and other statistics. They determine the shape of the distribution function of returns. These descriptive statistics display dynamics over time. Moreover, they can interreact within the given financial or capital market and among markets. We use the FX currency cluster represented by some of the major currencies and currencies of the Višegrad group. In analysing capital markets in terms of equity indexes, we chose developed markets, such as DAX 30, AEX 25, CAC 40, EURSTOXX 50, FTSE 100, ASX 200, SPX 500, NASDAQ 100, and RUSSEL 2000. We aim to check the changes in descriptive statistics, matrices of correlation concerning exchange rates, returns and volatility based on the data listed above, surrounding two crises: the global financial crisis (GFC) in 2007-2009 and Covid 2019.
\end{abstract}

Keywords: contagion, correlation, exchange rates, returns, volatility, GFC in 2007-2009, Covid 2019

\section{Introduction}

In the financial literature, one cannot find a precise and unique definition of contagion on financial markets. The term contagion is well known from immunology. It has also been widely used in sociology and psychology. Recently, this notion has been used

*Corresponding author, email address: kbrania@zarz.agh.edu.pl

Received 16 March 2021, accepted 26 May 2021 
broadly in analysing financial crises, and researchers have focused on different channels and aspects of them that are widespread among companies and financial markets. The term was first used during the Asian financial crisis in 1997. However, this phenomenon occurred much earlier.

Research on contagion started after 1997. The researchers established that approximately since the England-Latin America crisis of 1825, contagion has occurred in many known crises. They have happened almost every decade. Nowadays, contagion belongs to the standard economic terminology and fears of contagion must be seriously taken into account by economists and politicians.

In the economic literature, it is widely accepted that the financial crisis of 2007 -2009 was the first large global crisis since the Great Depression of 1929-1932. The crisis started in the United States in the moderate segment of the lending market, the sub-prime mortgage market. Unfortunately, it rapidly spread across all economies, both highly developed and emerging. It also spread across economic sectors. It especially affected almost all equity markets and currency exchanges rates over the world. Many countries were affected by this crisis even more severely than the equity market crash in the United States. These observations were starting points for the discussion concerning the presence and sources of 'contagion' in equity markets and FX markets.

In the vast majority of financial literature contributions, authors have focused on the co-movements of financial variables before and during a crisis. Contagion may start from an (important) country or the global financial sector, causing a high co-movement of domestic sector portfolios within the country or global factors. The first type of contagion is called domestic contagion (e.g., if the crisis originates in the USA it is called US contagion). Contagion originating in the global financial sector is called global contagion.

A very interesting research problem is the channels of contagion. There are two distinct types of channels formulated in the two alternative hypotheses. The first of them, called the globalisation hypothesis implies that contagion during crises is most visible concerning the economies that are highly integrated globally. The reason for the interrelation may be international trade and financial linkages.

According to the second hypothesis, also called the wake-up call hypothesis, a crisis initiated in one market segment or country delivers new information that may convince investors to revise their assessment of the condition of other market segments or countries, which transmits the crisis to other markets and countries [26, 37, 5]. From this hypothesis, it follows that domestic fundamentals may be the main reason for the transmission of the crisis. In the opinion of other researchers, the contagion may be caused by herding behaviour, which is widely observed in finance, or investors' risk appetite without the impact of fundamentals, or not dependent on actual fundamentals. Most of the studies present empirical results in favour of the second hypothesis.

In comparison to capital markets and other financial markets, the forex market exhibits unique and important features [45]. They enhance the study of contagion on the 
forex market. Firstly, unlike other financial markets, the forex market is non-centralised. This means that it has no central trading location, and traders can find competing rates from global dealers without problems. Secondly, the forex market is open 24 hours a day. Therefore, trading is synchronised [8]. Thus, the transmission mechanism of financial crises in the forex market differs from that in other financial markets. Thirdly, the forex market has the largest trading volume and liquidity of all financial markets. Therefore, it can directly or indirectly influence other financial markets [45]. And last but not least, the property is that the forex market connects a country's economy and trades with those of other countries. To summarise, the forex market affects the balance of international payments and the development of the domestic real economy, and thus it plays a vital role in national security and social stability. Hence, besides the capital market, we have also included the forex market in our study.

In the next section, we will review the literature on contagion on capital and forex markets with a focus on empirical results.

\section{Literature overview}

Over the past few decades, different parts of the world have faced financial crises. Not only developing but also developed economies have suffered as a result of these crises. The examples of the crises include the Mexican peso collapse of 1994, the Asian financial crisis of 1997 caused by the devaluation of the Thai baht in 1997, the devaluation of the Russian ruble in 1998 which had an impact on global financial markets, e.g., on quite different markets such as in Brazil, Thailand and even the United States, and the most important crisis in the first decade of the 21st century - the global financial crisis (GFC) 2007-2009. The outbreak of the coronavirus disease 2019 (Covid-19) pandemic has been an unprecedented shock to the global economy. The present Covid-19 crisis has affected not only the real economy but also the financial sector.

In the financial literature, it is typically assumed that a significant rise in the correlation or co-movement of stock markets reflects the contagion effect. However, disregarding numerous papers on contagion and its frequent use to describe the international spread of financial crises, there is still a controversial discussion about this important notion in economics and finance. Different definitions of contagion are cited in, e.g., $[12,11,2333,16,43,9,21,41,13]$.

Most contributors emphasise that if a shock to the financial market of one country is transmitted to another country, we can distinguish two situations: if the latter country is not interrelated through trade, bank loans or other investment flows with the first one, then this transmission can be accounted for by contagion. Otherwise, we do not qualify it as a contagion. Similarly, when shock to one country causes a rise in interdependence on the local or even global market, we may observe contagion. In the case of a major 
global shock, e.g., an increase in the price of oil across the world, despite increased comovement in markets, it does not qualify as a contagion.

In the 1990s, it was widely accepted that the collapse of the exchange rate in one country may indicate that another country in similar macroeconomic circumstances is more likely to abandon its fixed parity. Another type of contagion model is called the spillover model, which originated in trade linkages. This type of contagion was introduced by Gerlach and Smets [25]. According to this model, an attack-induced devaluation in one country increases its competitiveness. As a consequence, this leads to trade deficits and causes a decline in reserves for its trading partners. Therefore, their currencies become more susceptible.

However, Masson [37] stresses that true contagion refers to the simultaneous occurrence of currency crises that are not linked to macroeconomic fundamentals. In his model, a crisis is the result of an aggravation of the current account, reflecting, in turn, extremely high debt service. Interest rates contain a devaluation premium. As a consequence, the expectation of a devaluation can be self-fulfilling. Masson's argument focuses on the occurrence at the same time of several such episodes, rather than a causal link between them. Some authors think that contagion concerning currencies may be of a political nature. The goal of a decision is "primarily" political when it supports a political goal conflicting with an economic objective, i.e., to maximise votes income can be redistributed, and, as result, a devaluation decision has to be made. The arguments in favour of political contagion are cited by Drazen [15].

According to the most recent literature, e.g., Wang et al. [45], the notions widely used in finance are co-called shift-contagion driven by economic fundamentals and pure contagion induced by international trade and foreign direct investment. In this most recent publication, the main topic is the problem of contagion on the forex market during the 2007-2009 global financial crisis based on empirical analyses of 39 currencies that were actively traded on the forex market during the period 2005-2009. The authors adopt the econometric methodology of Gravelle et al. [27] to detect the nature of contagion (contagion induced by economic fundamentals or investors). Finally, using the DMC-EVT model, the authors established whether the financial (investor induced) contagion is a result of wealth constraints or portfolio rebalancing behaviour. Their empirical results confirmed the existence of financial contagion on the forex market in the chosen time frame and supported the conjecture that the contagion channel was wealth constraints [45].

In the opinion of some economists, contagion can recognise only specific types of interdependencies, e.g., the transmission of the most extreme negative events. According to another point of view, the only residual transmission of shocks after accounting for "fundamentals" constitutes contagion. Contagion is not "rational" investor action concerning shocks through financial markets, although irrational behaviour is contagion. From these points of view, it follows that for the notions linkages or rational be- 
haviour, the strict definitions of contagion are not easy to implement for practical purposes. Some global shocks from the world's largest economy - the U.S. - i.e., a change in the interest rate or rate of growth were not classified as contagion. However, the impact of the subprime crisis in the U.S. in 2007 on the rest of the world was classified as a contagion.

Many researchers try to analyse the interrelations between developed and emerging markets. Such linkages are studied by Chen et al. [10], Kim et al. [34], Syllignakis and Kouretas [40], Ho and Huang [29]. However, the conclusions of these studies are not unique. The dependencies between European markets in the long term were the subject of studies by, e.g., Voronkova [43], Černý and Koblas [9], Égert and Kočenda [21], Syriopoulos [41], Czapkiewicz and Wójtowicz [13]. These authors use cointegration and fractional cointegration concerning returns of European developed and emerging stock markets from the CEE countries. In the short term, these scholars detect similar interrelations as reported in previous literature. Hanousek et al. [28] find an essential spillover impact on the stock markets of CEE countries. Égert and Kočenda [21] compute the time-dependent correlations between the intraday returns of indexes BUX, PX50, and WIG20.

The rising correlation between markets after the beginning of a crisis implies that a decline in one of the stocks can be accompanied by a decline in the others. This is a result of the frequently observed contagion effect between stock markets. The creation of a welldiversified portfolio is not possible without checking for possible contagion. According to, e.g., Forbes and Rigobon [23], contagion can be found if interrelations among markets are larger during turbulent times than in quiet times. They explain the reason for the change in transmission channels and mechanisms during a crisis, first of all, why cross-market linkages increase after a shock. According to the opposite group of theories, channels and transmission mechanisms do not change during a crisis [38].

We stress that the contagion effect does not occur when two markets are essentially correlated during both types of time (turbulent and quiet). It is widely accepted in financial literature that contagion occurs in a situation where the financial markets are more strongly correlated in turbulent times than during quiet periods. The contagion effect between two markets occurs when a significant increase in the correlation during a turbulent period can be observed.

The World Bank defines three forms of contagion, i.e., a broad definition, a restrictive one, and a very restrictive one [32]. The broad understanding of contagion defined by ECB (When a crisis in the stock market of one country causes a crisis in the stock market of another country this can be thought of as financial market contagion) is associated with the cross-country transmission of shocks. This form of contagion applies if general cross-country spillover effects are observed. In the light of this definition, contagion is not necessarily related to crises. The restrictive definition of contagion supposes the transmission of shocks to other countries or a cross-country correlation. According to this definition, transmission cannot be explained by fundamental dependence 
among countries or as being caused by common shocks. This definition is strongly related to an excess co-movement. The last is usually explained in the finance literature by herding behaviour. The very restrictive definition of contagion supposes the detection of contagion when cross-country correlations increase during times of crisis, i.e., during quiet times correlations are much lower [38]. Dornbusch et al. [14] understand contagion as a considerable increase in cross-market dependencies after a shock has affected a country or market, determined by changes in stock prices or financial flows after a shock with co-movement in quiet times.

To detect contagion, some authors use the methodology of causality concerning mean returns. Ho and Huang [29] check causality in variance. The contribution of Abdennadher and Hellara [1] is along similar lines to this research. They prove the interdependence of stock market volatilities, taking into account different capital markets. They check the effects of the Global Financial Crisis (GFC) on the dynamics of dependencies over the selected time. Jung and Maderitsch [31] check contagion in volatility based on stock market intraday data in the period 2000-2011 in Hong Kong, Europe, and the United States. They establish the dynamics and structural breaks in volatility spillovers. According to them, their results are in line with the notion of contagion.

In their paper on contagion, Savva and Aslanidis [39] check this effect based on constant conditional correlation (CCC), and smooth transition conditional correlation (STCC) models. Their empirical results based on the Polish, Hungarian, and Czech stock markets show lower correlations with small CEE markets than with countries from the Euro area. Syllignakis and Kouretas [40] use dynamic conditional correlation (DCC) GARCH models to establish that the 2007-2009 world crises essentially shifted the conditional correlation between the leading developed markets (Germany and US) and emerging CEE markets. Baruník and Vácha [4] employ wavelets to check contagion effects between CEE markets. Using wavelets methodology, they found a contagion effect between the German and Czech stock markets.

Durante et al. [16-20] used their methodology to check changes in stock market co-movements. They introduce the notion of spatial contagion and apply copula methodology. Instead of comparing correlations before and after a crisis, they compare the correlation for extremely low returns (in the left tail of returns distribution) with the correlation around the median. This definition is appropriate for the extreme losses on the markets under investigation. Their empirical conclusions are in line with the results of Longin and Solnik [35] who detect a higher correlation in the case of large negative returns. In a more recent study, Massad and Andersen [36] apply methods of dynamics detection of three different channels. In their model, market behaviour influences the decision-making process.

Fry-McKibbin et al. [24] implement new joint tests for contagion problems in Eurozone equity markets. Their research is based on the data from the subprime crisis of 2007-2008, the global financial crisis (GFC) of 2008-2009, and the European debt cri- 
sis of 2010-2014. The authors stress that contagion is transmitted by higher-order moment channels. In addition, although it was not found using traditional tests based on correlations, the contagion was detected thanks to new tests. Huynh et al. [30] assess the contagion risk for the returns of commercial banks employing non-parametric methods and copulas. They detected significant contagion risk. They also find high dependence between correlations and the structure of the stock returns of the analysed banks.

In our study, we employ the exchange rate data from the forex market and levels of selected stock indexes from both developed and emerging markets. We aim to investigate the correlation behaviour on both markets using crucial financial variables, namely returns and return volatilities. These analyses are conducted around the beginning of the two greatest crises of the twenty-first century: GFC and Covid-19. We compare empirical results in several dimensions: movement of the correlation of variables under investigation, the differences and similarities in correlation concerning returns and returns versus volatility in both markets, what channels of contagion transmission are more important exchange rates and/or volatility on the forex market, and returns on the forex market and/or volatility on the capital market. Therefore, we try to compare the correlations between the given variables within the market and between the markets. Since the Covid-19 crisis still has not been overcome, our comparison of both crises concerning contagion is very preliminary.

This research has allowed us to test some conjectures formulated below based on economic literature and preliminary computations.

Conjecture 1. Under stress conditions (i.e., around GFC 2008 and Covid-19), for some pairs of instruments under consideration, the clear impact of these two events on the correlation coefficients is visible. They have increased considerably (in absolute value) in most cases, which has supported the appearance of the contagion phenomenon on the markets under consideration. Indexes in the study mainly represent selected European markets and American markets. Because of economic integration within the framework of the European Union, we expect that the following hypothesis might hold.

Conjecture 2. The contagion between indexes from the same group (European indexes and American indexes) is stronger than that between indexes coming from different groups. Forex markets are nowadays less speculative than stock markets. Therefore, we expect that:

Conjecture 3. The contagion in terms of returns and volatilities is less pronounced on the forex markets than on the stock markets. 
The GFC 2008 and Covid-19 were caused by quite different reasons and spread via different channels. The financial crisis was primarily caused by deregulation in the financial industry.

In 2004, FED raised interest rates. As a consequence, house prices began to decline in 2007 as supply became greater than demand. This trapped homeowners who were not able to pay, but could not sell their houses. GFC 2008 hit primarily developed economies hard. Emerging economies increased their share in total global output during the 2008 -2009 financial crisis (they now account for $58 \%$ of the global economy).

At the very beginning of the Covid-19 outbreak, economic forecasts were also very pessimistic for the developed world but the situation was not so bad for underdeveloped countries. However, over the following months of the Covid-19 pandemic, these predictions were revised. In 2020, and especially in 2021, emerging economies, excluding China, were attacked by coronavirus much stronger than developed countries. These countries have worse health systems. They could not be at the beginning of the queue for coronavirus vaccines. The most important reason was that they did not have sufficient credibility in financial markets to borrow money. Emerging countries were not rich enough to shield their populations from the income losses resulting from Covid-19. Therefore, a considerable delay in the forecasted catch-up of their living standards with those of the developed economies is expected. Developing countries entered the pandemic along a path of significantly slower growth than expected before Covid-19. Losses in Latin America can reach 6\% of GDP and approximately 8\% of GDP in emerging Asian economies other than China.

Since the indexes under consideration primarily reflect the performance of developed financial markets, and developed countries have suffered less from the pandemic than other countries, we expect that:

Conjecture 4. Contagion in the case of the Covid-19 pandemic is less pronounced in terms of correlation than during GFC 2008.

This hypothesis will be tested in the empirical chapter of this paper. The remaining part of this paper is organised in sections and subsections. The dataset used in the study is described in Section 3. Section 4 discusses empirical results presented in tables and visualised in figures. The last section concludes the paper.

\section{Datasets}

We use data from both foreign exchange and capital markets. For the FX cluster, we decided to analyse some of the major currencies and currencies of the Višegrad group, i.e., EUR/USD, EUR/CHF, USD/CHF, EUR/HUF, EUR/PLN, EUR/CZK, USD/CZK, 
USD/HUF, USD/PLN, CHF/PLN, CHF/PLN, CHF/CZK, CHF/HUF, PLN/CZK, and PLN/HUF. In terms of equity indexes, we have chosen developed markets, i.e., DAX 30, AEX 25, CAC 40, EURSTOXX 50, FTSE 100, ASX 200, SPX 500, NASDAQ 100, and RUSSELL 2000.

We used the OANDA data bank. This provides data only for instruments tradeable on its platform, therefore it limited the scope of potential variables that could be researched. However, we deem the list of variables analysed to be wide enough to formulate research problems and perform a quantitative analysis. A Python script was developed to fetch data from the interface provided by the company OANDA (one of the leading financial brokers facilitating access to multiple financial products for both professional and retail clients), called REST-V20 API. This API allows users to download candlestick data in JSON (Java Script Object Notation) format. Also, necessary data wrangling operations were applied to convert the data to a more convenient format (data frames). The data frequency chosen is $5 \mathrm{~min}$ as we deem it a good compromise between the accuracy of intra-day data and noise associated with extremely high frequencies. The data is described in extensive tables in the Appendix, where we provide the following statistics: mean, median, standard deviation, minimum, maximum, skew, and kurtosis.

Tables 1-8 in Appendix present descriptive statistics for, respectively, FX returns, equity indexes returns, FX volatility, and equity indexes volatility. Each of these four cases is analysed both for the 2008 financial crisis period and the Covid-19 crisis. As expected, we can observe more extreme values after the market shock. This is strictly associated with a significant increase in volatility between all the markets under consideration. A key observation is also the higher absolute value of skewness and higher kurtosis (both for returns and squared returns). For equity indexes returns, we observe decreased, negative returns after the crisis event, which is in line with intuition (in crisis, capital tends to flow from risky assets, such as stocks, to safer ones, for example, cash or bonds). For FX returns, there is no clear pattern, but we can conclude that there is a fly-to-safety effect too - investors prefer to put money in more liquid currencies that are considered safe havens - such as USD, EUR or CHF as opposed to niche currencies that are more vulnerable to speculative attacks (following from the size of the markets and their liquidity themselves), such as PLN, CZK or HUF.

\section{Empirical results and their economic discussion}

The main focus of this research was to examine the financial contagion effect on equity indexes and foreign currency pairs - the two asset classes that are popular among both retail and professional investors. As factors that catalyse the effect, the largest twenty-first-century financial crises are considered to be: 


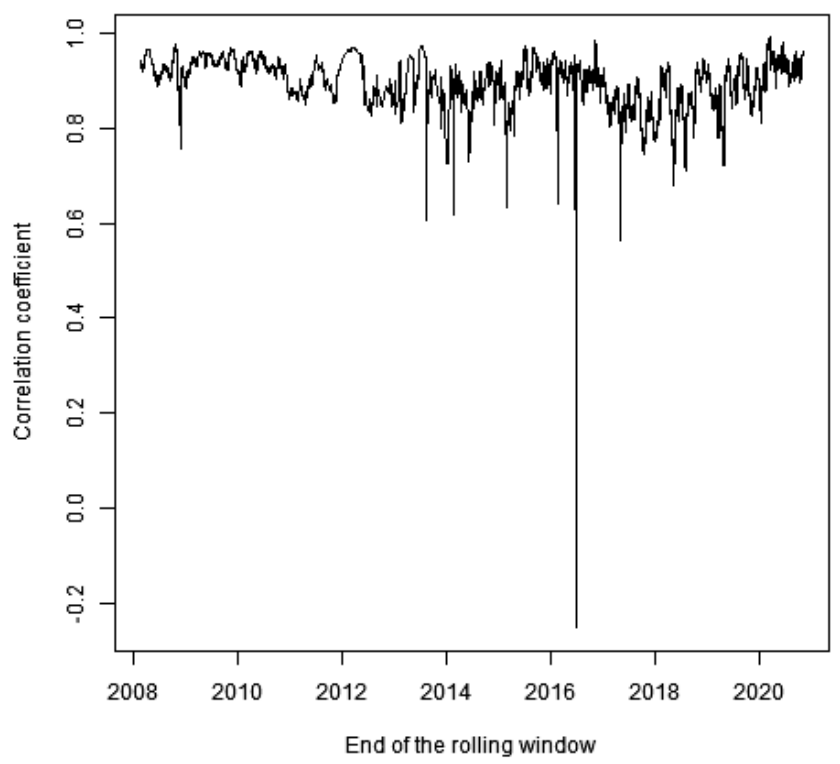

Fig. 1. Dynamics of the correlation coefficient between logarithmic returns of DAX30 and CAC40 Indexes in the rolling window of 1000 consecutive observations (based on OANDA's price data)

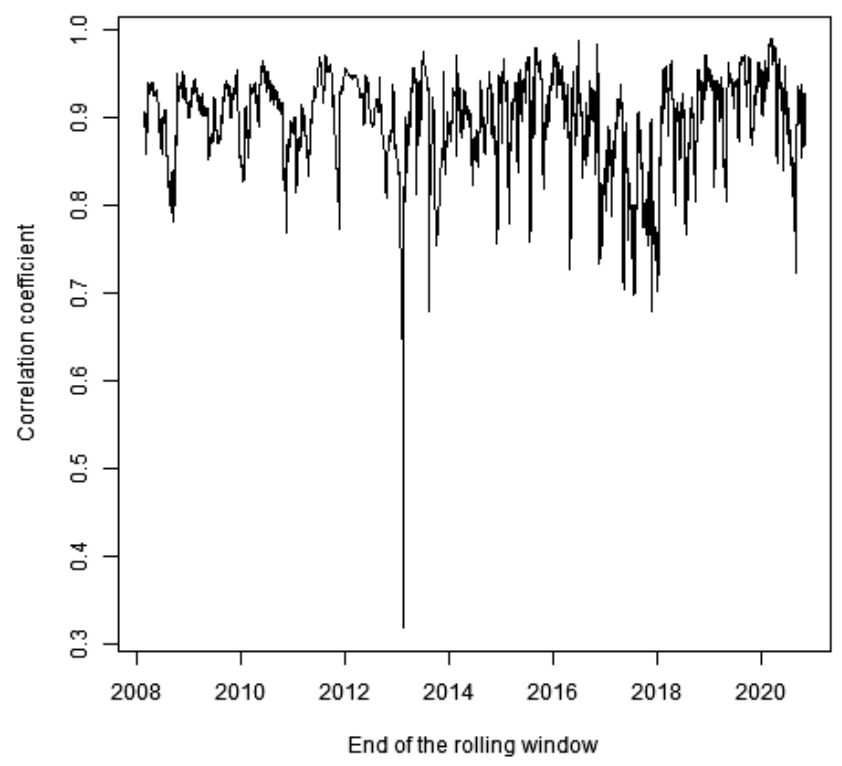

Fig. 2. Dynamics of the correlation coefficient between logarithmic returns of indexes S\&P500 and NASDAQ in the rolling window of 1000 preceding observations (based on OANDA's price data) 
- The financial crisis of 2008, also known as a global financial crisis which was caused by a growing housing bubble and excessive risk-taking practices in the financial industry. As a start date, we assume September 15th, 2008, the bankruptcy of one of the largest financial institutions, Lehman Brothers. At the time, it was the deepest global recession since the Great Depression.

- The COVID-19 recession, global economic crisis associated with the most severe worldwide pandemic since Spanish flu (also known as the 1918 influenza pandemic). As opposed to the 2008 crisis, it is not connected to malpractices in the financial industry, but a real decrease in economic activity in most sectors, especially the service industry, due to lockdown regulations imposed by most governments. In terms of scale and pace, the COVID-19 recession has been even more devastating than the global financial crisis of 2008.

This research paper focuses on the dynamics of closing prices (measured by logarithmic returns at 5-minutes intervals) and their volatility (proxied by the squared logarithmic returns time series). It is very common in the financial literature to aggregate tick-by-tick data into intervals of some length. This length should enable to observe changes in financial variables even in less liquid times. In addition, due to aggregation into 5-minutes intervals, we can significantly reduce the amount of data from the period under consideration. Core computations were performed in $\mathrm{R}$ language using RStudio programming interface (only the data preparation part was completed using the PyCharm Integrated Development Interface (IDE) for Python language).

Figures 1, 2 illustrate examples of how rolling correlations change over time. The applied rolling window is 1000 consecutive observations (5-minute intervals). One notices that the correlation coefficient varies over time, although for markets/economies that are connected, we can expect that the correlation tends to lie in some channel between relatively high bounds (for example, for closely related European equity indexes or between different indexes in the American market). This is in favour of Conjecture 2. Taking into account the fact that under stress conditions, for some pairs of instruments under consideration, there is a clear impact on the correlation coefficients, i.e., its increased absolute value (for a positive correlation, it moves closer to 1 , for a negative correlation, it moves closer to -1) our first research hypothesis (Conjecture 1) also holds.

We examined similar charts for all possible pairs of instruments - separately for FX, 91 pairs and indexes, 36 pairs. Both logarithmic returns (proxy for returns) and squared logarithmic returns (proxy for volatility) were taken into account. The main observations and conclusions are listed below in subsections including returns around GFC 2008 and Covid-19 and volatilities.

\subsection{Contagion in returns}

Indexes returns. We observe two clusters of variables with high pair correlations among the group. This observation supports Conjecture 2. In the first cluster, there are 
American indexes: S\&P 500, NASDAQ, and RUSSELL 2000. This is in line with economic intuition - as they belong to the same economy, we can expect strong interdependencies between the constituents of the indexes. An interesting case is NASDAQ, which is based on high-tech companies which have shown good resilience in the COVID-19 crisis (or even leveraged the new opportunities to strengthen their market positions). In the second group there are all European indexes under consideration, and, surprisingly, NIKKEI.

Most of these high correlations can be explained by strong economic relationships between European Union economies. For the EUROSTOXX 50 index, this even follows from the construction - as it includes major European companies which also heavily contribute to the performance of national indexes. The general behaviour of highly correlated indexes under extreme stress conditions associated with both crises is reflected in a further increase in the correlation.

FX returns. As opposed to the equity markets, it is difficult to summarise the correlation dynamics between FX returns in terms of simple rules. For stock market indexes, the global effect comes from the risk aversion of a significant number of investors; they tend to transfer their funds from stocks to safer asset classes or even cash under extreme stress conditions. This phenomenon is less pronounced for the currency market, because, if some currencies relatively depreciate, some of them must relatively appreciate. Usually, the capital flows from riskier emerging markets to those considered as safe havens in the so-called fly to safety effect. It is also worth noting that many idiosyncratic features impact the reaction of investors, to name a few: domestic interest rates/inflation, government reaction to crisis, central bank policy (including standard practices, like foreign exchange reserves, capital requirements for commercial banks or unorthodox tools, like quantitative easing, etc.) As based on the above factors and assessment of the risk-to-reward ratio (which depends on the investor's risk appetite), market participants drive the dynamics of FX markets in the classic model of supply and demand price discovery.

\subsection{Contagion in volatilities}

Indexes volatility. The global effect of increased correlation is noticeable under the conditions of both crises under consideration for all pairs of indexes. However, it seems to be a short-term effect. Rolling correlation series themselves are volatile.

FX volatility. FX volatility is opposed to the volatility of equity indexes; there is no clear rule of thumb. Moreover, the relationships between FX pairs look different in the case of the COVID-19 and Lehman Brothers crises - in the former crisis volatility decreases from relatively high positive regimes to rather low positive regimes, while in 
the latter crisis volatility remains strikingly similar for most of the pairs of variables examined. Over the long term, one can claim that the time series of rolling correlation coefficients are highly volatile. These findings are in favour of Conjecture 4.

Figures 3-10 capture the properties and confirm the conclusions. We show FX returns, equity indexes returns, FX volatility, and equity indexes volatility, respectively, both under the conditions of the 2008 financial crisis of the COVID-19 crisis conditions. The contagion effect is strongly visible for the correlation of equity indexes, both for returns and volatility (correlations increased from high to very high positive regimes, for both crises).

However, for most indexes, a rise in correlations in terms of both returns and volatilities is slightly larger, around GFC 2008, than around Covid-19, which partly supports Conjecture 4. Interestingly, there is one exception to the correlations between the Australian index and other indexes, observable in the 2008 crisis - positive correlations only slightly decrease after the market shock. This phenomenon can be explained by the structure of the Australian economy - it is a big exporter to China and South-East Asia, which were not impacted by the Lehman Brothers crisis on a comparable scale. On the other hand, the contagion effect is not empirically supported for correlations between FX pairs, which supports Conjecture 3. The most appealing economic reason is the less speculative character of the foreign exchange market and its property that it reacts more to a fundamental situation in economies rather than to price action or sentiment on the market. We can observe some movements of the correlation coefficient only for a few pairs of FX variables - these potentially come from the general flow of cash in a more risk-averse environment - capital is transferred from more risky, immature markets to economies that are considered safe havens - such as the United States, Japan, Switzerland or the Eurozone.

Figures 11-14 present the performance of simple linear models (without intercept term) in the 3-month time windows preceding and following the crisis events. For both returns and volatility, we picked examples of highly correlated indexes (DAX 30 and EUROSTOXX 50) and moderately correlated indexes (EUROSTOXX 50 and S\&P 500). From these examples, it is visible that a crisis event (for both considered market stress periods) changes the relationship between the variables mentioned above, as we can observe a significant increase in $R^{2}$ value. In the crisis period, a large portion of the variable's variance can be described by variance in the explanatory variable, which is a useful observation for investors in the context of risk management (for instance, a long position on one index can be effectively hedged by a short position on another index - such a strategy would display a significantly smaller risk measured as P\&L volatility). We were able to draw strikingly similar conclusions for the vast majority of indexes pairs considered. We also looked at returns - volatility relationships, but these are generally not very convincing. 


\subsection{Economic implications of empirical results}

Nowadays, retail investors use more and more sophisticated tools in their trading activity. One of them is so-called pair trading, and it is usually applied to equity markets. The main principle of this strategy is to pick strongly correlated instruments and build a relevant risk-neutral position (if these assets are positively correlated, one should enter a long position for the first instrument and a short position for the second instrument, as opposed to a situation of negative correlation, which would require entering a long or short position for both assets). The empirical research conducted in this paper supports the validity of this approach in turbulent times for financial markets - for example, if one applies pair trading to indexes, a reduction in total position volatility and associated risk are expected (especially compared to the single instrument position).

On the other hand, this phenomenon can also be leveraged by financial institutions (to name just a few: brokerage houses, investment banks, pension funds, etc.). Usually, these entities are strictly supervised by regulatory bodies (who are mandated to protect the stability of financial systems, to reduce systemic risk and to represent the interests of weaker market participants) and their shareholders (who aim to maximise the profit earned by the organisation). All major financial institutions are required to maintain reserves that are associated with different forms of risks taken by them. Therefore, if the empirical relationships between some of the instruments decrease the overall risk of the portfolio, there is an outright financial gain linked to the reduction in some of the mandatory reserves. The returns and volatilities of financial instruments are not the only factors that these institutions should take into account. For instance, there is a high probability that the order flow from clients will also be correlated during the stress period (long limit orders will be filled in multiple indexes during a market crash and many of the short positions will be closed by taking profit orders). Therefore, risk management systems should be designed in a way that allows live monitoring of the overall risk and portfolio imbalances that may occur during turbulent market times. Decision-makers should keep in mind that it is not possible to entirely mitigate the risk - usually, our actions transfer just one type of risk to another (in this example we would see an increased correlation risk).

Another trading strategy that would be successful in a contagion environment is correlation trading. This technique stems from the difference between the future realised correlation and the implied level of correlation derived from the indexes' derivatives. This would involve building a relevant position from call/put options or straddles or using variance/correlation swaps. Due to the high complexity of such strategies, involving sophisticated financial derivatives, proper execution can be carried out only by specialised trading teams employed by financial institutions or very experienced and knowledgeable individual investors. However, the basic principle of such a strategy is relatively simple - it aims to leverage the fact that the correlation observed in the future will be significantly greater/smaller than today's expectations. 

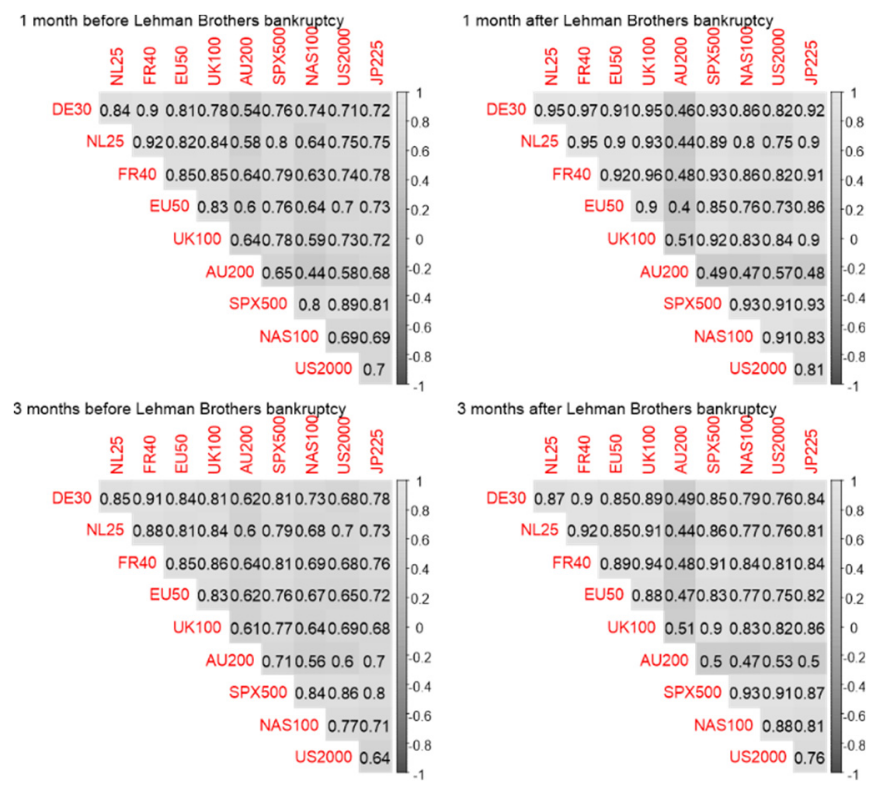

Fig. 5. Equity indexes correlation of returns around 2008 crisis. Correlation matrices between logarithmic returns of selected stock indexes in periods preceding and following Lehman Brothers bankruptcy considered the beginning of the Global Financial Crisis (September 15th, 2008) (based on OANDA's price data)
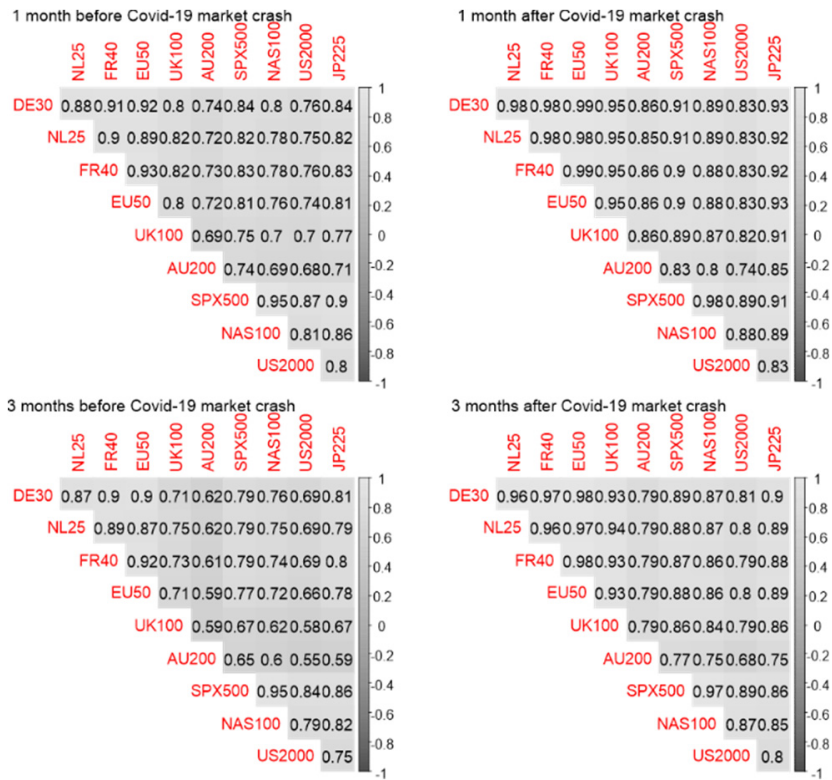

Fig. 6. Equity indexes correlation of returns around Covid-19 crisis. Correlation matrices between logarithmic returns of selected stock indexes in periods preceding and following the stock market crash associated with COVID-19 pandemic (began February 20th, 2020) (based on OANDA's price data) 


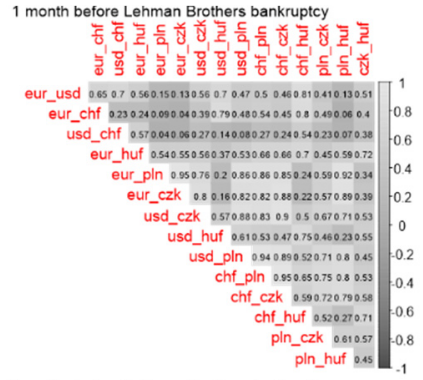

3 months before Lehman Brothers bankruptcy

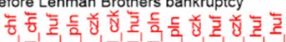

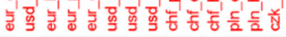

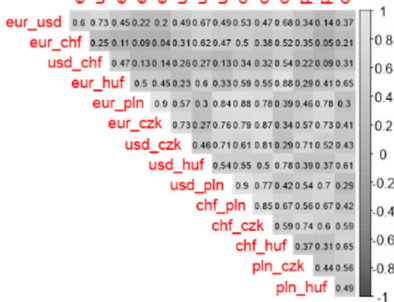

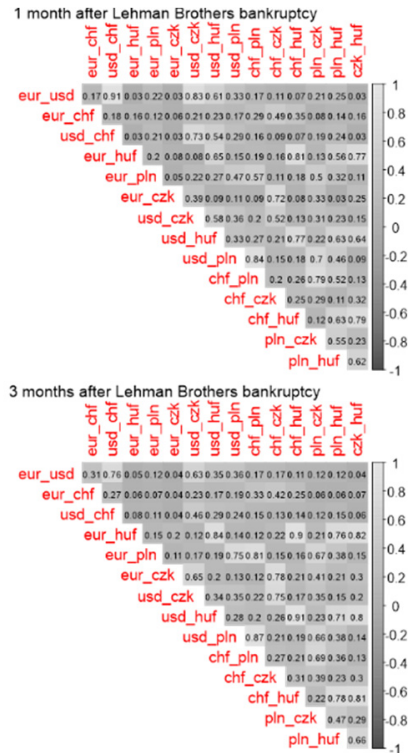

Fig. 7. FX pairs volatility correlations around the 2008 crisis. Correlation matrices between squared logarithmic returns of selected currency pairs in periods preceding and following Lehman Brothers bankruptcy which is considered the beginning of the Global Financial Crisis

(September 15th, 2008) (based on OANDA's price data)

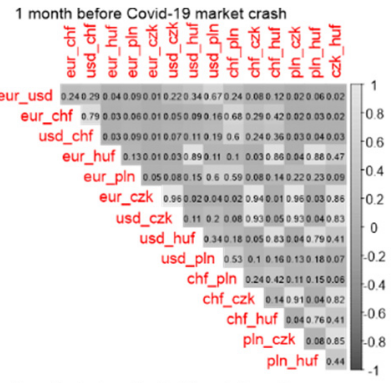

3 months before Covid-19 market crash

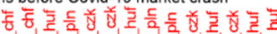

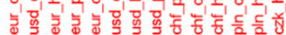

eur_usd 0.260410050.040 010.5205507902016015002004002

usd chf o o s 0.050 .02022024036059038044003003002

eur huf a1 0040.05075009008004073005083054

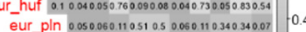

eur_czk 0.820 .030 .030 .030810030 .800040 .77

usd_czk 0.310.440.120780.1 0770050.68

usd_huf 0.510 .180 .120690050 .660 .43

usd_pln 0.450 .1601801902005

chf_pln 0.430550 .180 .180 .04

chf_czk 033077005067

chf_huf Dos05040

pln_czk 0160.75
1 month after Covid-19 market crash

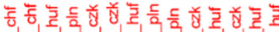

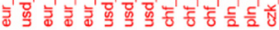

eur_usd 0260.850130040050520620650180130180080080011$]_{0}^{1}$

eur_chf 0.22004001002020202403402302500 .040 .010 .08

usd_chf 0.10030030 .40510520130 .070 .1400500601000

eur_huf 0.080 .080 .180670 .10170 .1090 .20 .580 .68 .

eur_pln 0.030.050 065 $0.450 .650 .030 .090 .390 .530 .07 \quad 0.4$

eur_czk $0.750000070050 .90 .070 .750 .080 .61 \quad 0.2$

usd_czk 0+ 0110180840210.44012057 usd_huf 0.40020 .160 .730 .130 .480 .48 - 0 usd_pln $0.720 .150 .150 .340 .460 .07 \quad-0.2$ chf_pln 0.150.260.460.610.13 chf_czk 0.150.750 000.61 chf_huf 0.190.570.67 -0.0 pln_czk 0.420.63 pln_huf 0.44

3 months after Covid-19 market crash

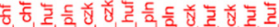

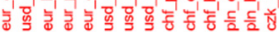

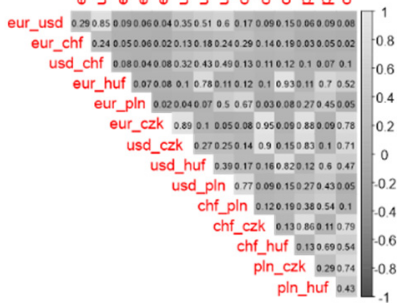

Fig. 8. FX pairs volatility correlations around the Covid-19 crisis. Correlation matrices between squared logarithmic returns of selected currency pairs in periods preceding and following the stock market crash associated with COVID-19 pandemic (began February 20th, 2020) (based on OANDA's price data) 

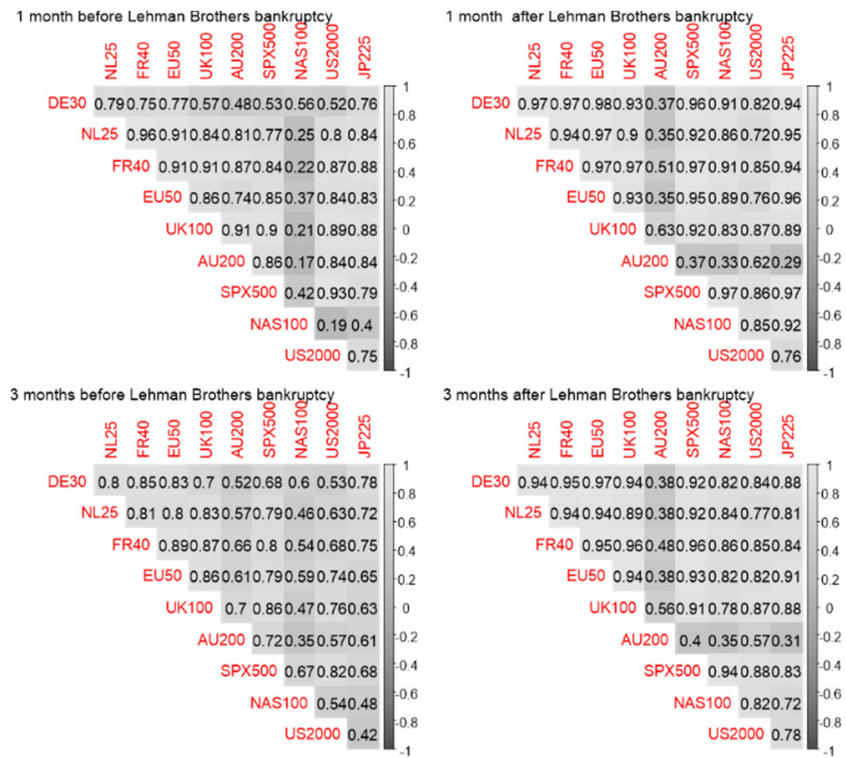

Fig. 9. Equity indexes volatility correlations around the 2008 crisis. Correlation matrices between squared logarithmic returns of selected stock indexes in periods preceding and following Lehman Brothers bankruptcy considered the beginning of the Global Financial Crisis

(September 15th, 2008) (based on OANDA's price data)
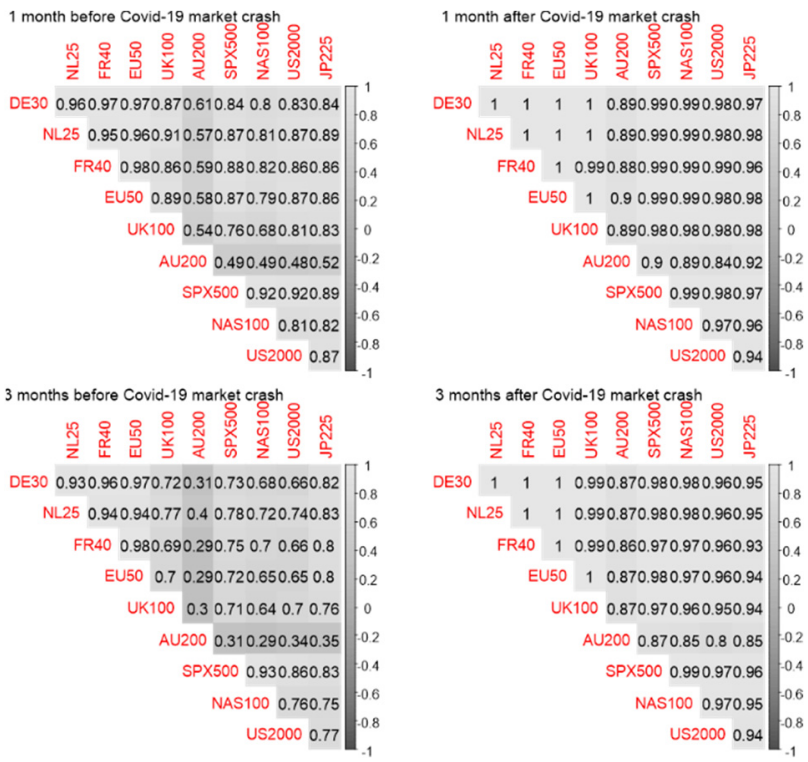

Fig. 10. Equity indexes volatility correlations around Covid-19 crisis. Correlation matrices between squared logarithmic returns of selected stock indexes in periods preceding and following the stock market crash associated with COVID-19 pandemic (began February 20th, 2020) (based on OANDA's price data) 

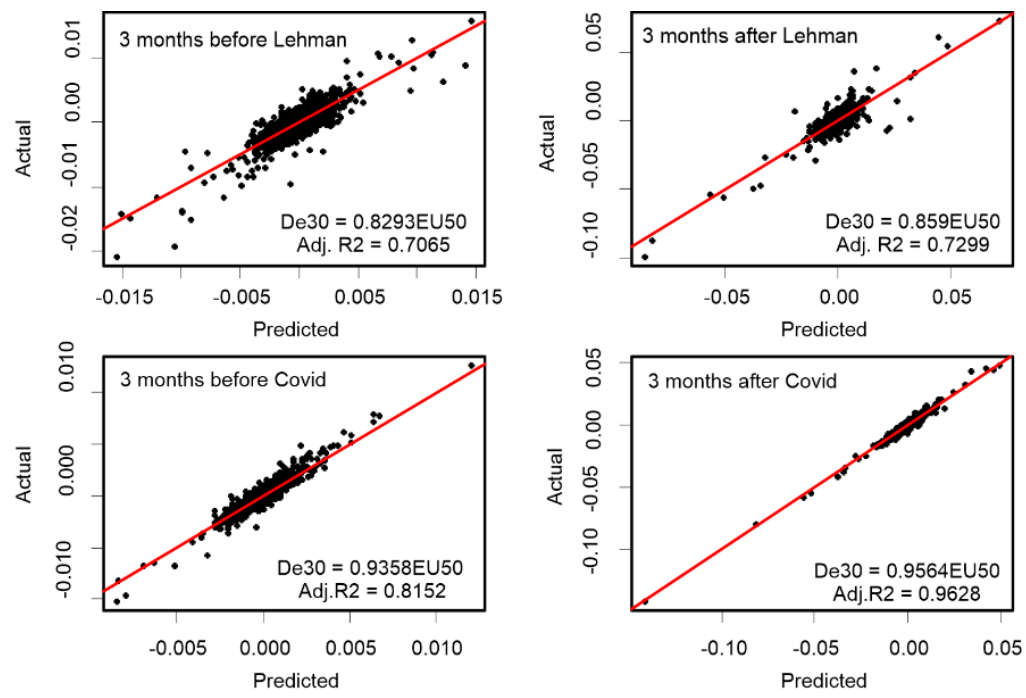

Fig. 11. Performance of simple linear models (without intercept) for highly correlated indexes (EUROSTOXX 50 and DAX 30) during the 3-month periods preceding and following crises events (logarithmic returns regressed on logarithmic returns). An increase in $R^{2}$ indicates improved explanatory power of models in the crisis periods compared to the pre-crisis time (based on OANDA's price data)
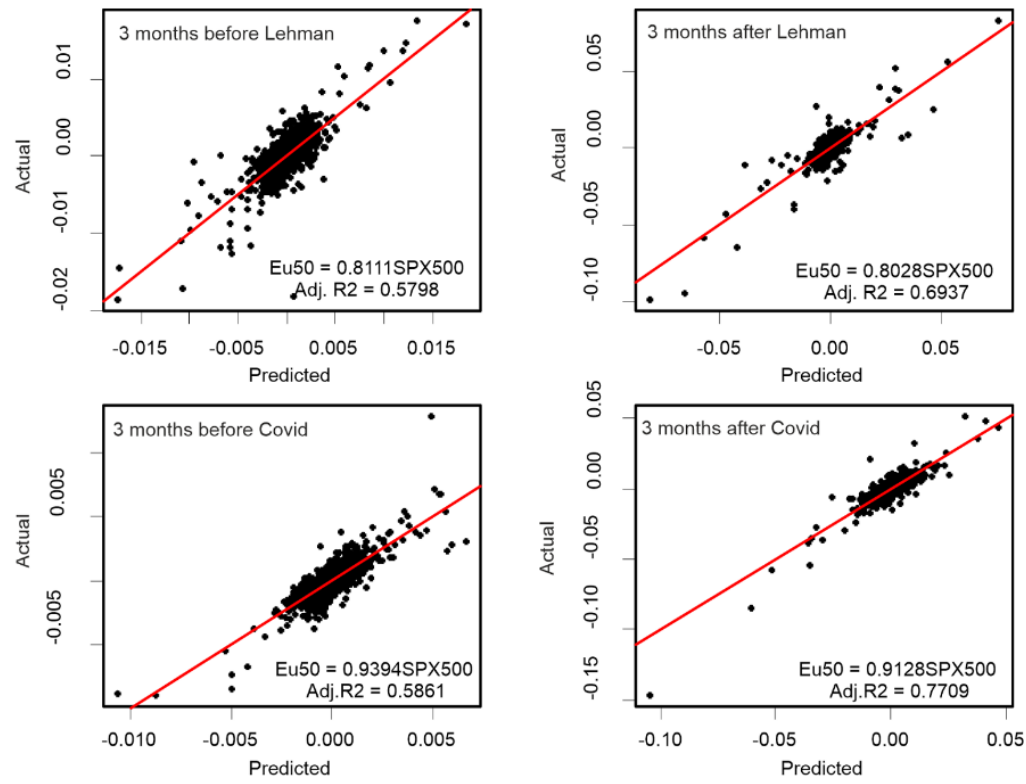

Fig. 12. Performance of simple linear models (without intercept) for moderately correlated indexes (EUROSTXX 50 and S\&P 500) during the 3-month periods preceding and following crises events (logarithmic returns regressed on logarithmic returns). An increase in $R^{2}$ indicates improved explanatory power of models in the crisis periods compared to the pre-crisis time (based on OANDA's price data) 

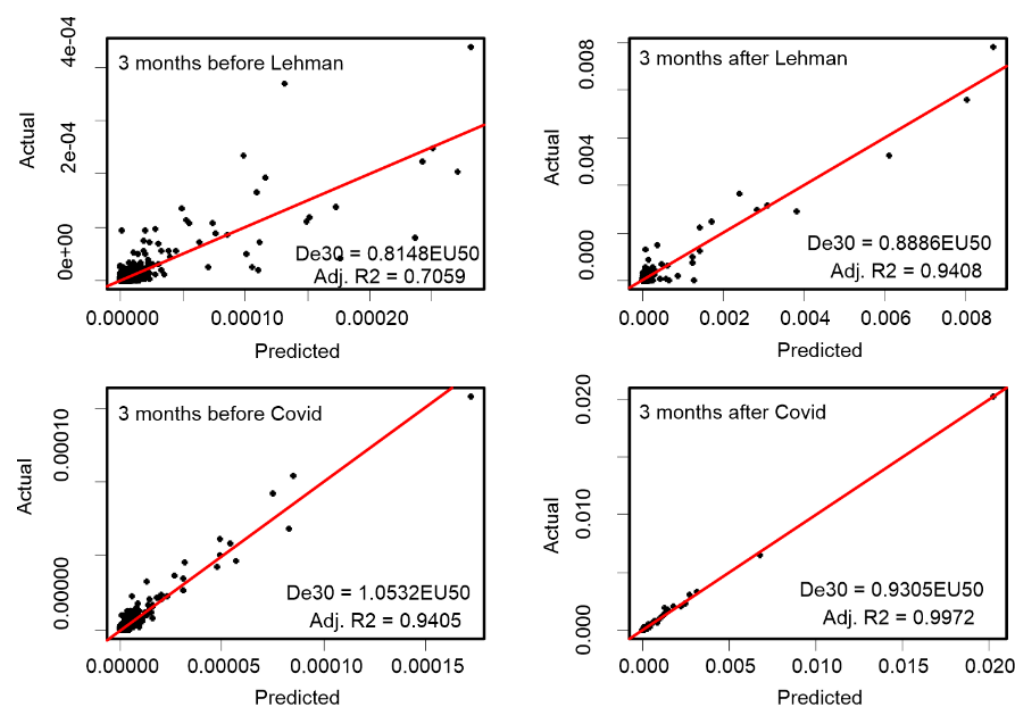

Fig. 13. Performance of simple linear models (without intercept) for moderately correlated indexes (EUROSTOXX 50 and S\&P 500) during the 3-month periods preceding and following crises events (squared logarithmic returns regressed on squared logarithmic returns). An increase in $R^{2}$ indicates improved explanatory power of models in the crisis periods compared to the pre-crisis time

(based on OANDA's price data)
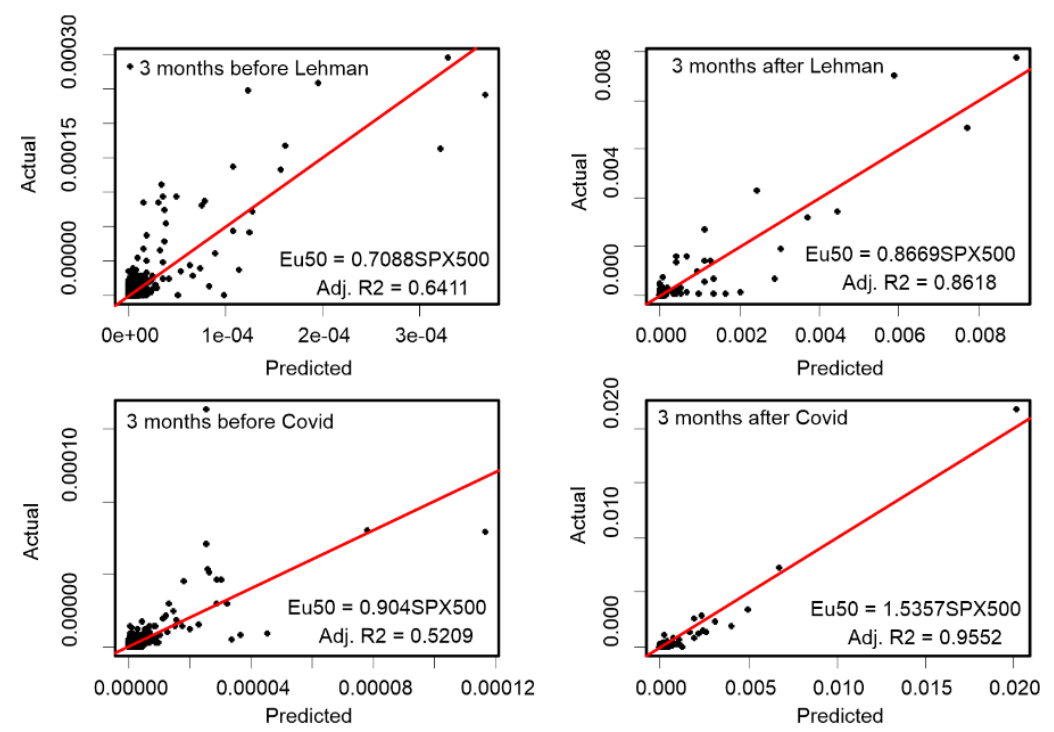

Fig. 14. Performance of simple linear models (without intercept) for moderately correlated indexes (EUROSTOXX 50 and S\&P 500) during the 3-month periods preceding and following crises events (squared logarithmic returns regressed on squared logarithmic returns). An increase in $R^{2}$ indicates improved explanatory power of models in the crisis periods compared to the pre-crisis time (based on OANDA's price data) 


\section{Conclusions}

In finance, contagion is understood to refer to the spread of an economic crisis from one market or region to another market or region. This phenomenon can be observed on either a domestic or international level. However, the vast majority of financial analysts, economists and investors relate contagions to the problem of global market interdependence and its fluctuations after upcoming financial crises. Contagion is usually recognised as a negative spillover from one crashing market to another. In our paper, precisely this understanding of contagion is the subject of empirical research based on several exchange rates and indexes.

Financial markets display very complex hidden dynamics. They are not described best in terms of one single financial variable, e.g., returns. A better description of contagion processes may be provided by including other variables simultaneously. In our comparative study, we apply returns and volatility in different time frames around the crises of 2008 and COVID-19.

Changes in financial and capital markets usually get ahead of processes in the real economy. The contagion effects on these markets are important because they can have serious negative consequences for the real economy.

From this study, it follows that around both crises contagion phenomena are essentially stronger on stock markets than on forex markets. Moreover, contagion effects on financial markets were more pronounced around the crisis of 2008 in comparison to the COVID-19 crisis.

This thorough analysis of figures and tables with computational results allows us to conclude that our conjectures might hold. However, since the COVID-19 crisis is not over, these preliminary conclusions should be revisited in future research.

Further research should also focus on retrospective complex investigations of the differences and similarities in the contagion of several crises and their channels, strength, speed of propagation, and impact on the real economy in the past.

\section{Acknowledgement}

The authors express their gratitude to the Editor and the anonymous referee for his/her valuable comments on an earlier version of the paper. This research was financed by AGH University of Science and Technology in Krakow (institutional subsidy for maintaining Research Capacity Grant No. 16.16.200/396).

\section{References}

[1] Abdennadher E., Hellara S., Causality and contagion in emerging stock markets, Borsa Istanbul Rev., 2018, 18 (4), 300-311. 
[2] BollersLEV T., Modelling the coherence in short-run nominal exchange rates: a multivariate generalized ARCH approach, Rev. Econ. Stat., 1990, 72, 498-505.

[3] Bai J., Perron P., Computation and analysis of multiple structural changes model, J. Appl. Econ., 2003, 18, 1-22.

[4] BARUníK J., VÁCHA L., Contagion among Central and Eastern European stock markets during the financial crisis, Fin. úvěr-Czech J. Econ. Fin., 2013, 63 (5), 443-453.

[5] Bekaert G., Ehrmann M., Fratzscher M., Mehl A., Global crises and equity market contagion, NBER Working Paper, No. 17121, National Bureau of Economic Research, U.S.A., 2011.

[6] Cappiello L., Engle R., Sheppard K., Asymmetric dynamics in the correlations of global equity and bond returns, J. Fin. Econ., 2006, 4, 537-572.

[7] Сна B., OH S., The relationship between developed equity markets and the Pacific Basin's emerging equity markets, Int. Rev. Econ. Fin., 2000, 9 (4), 299-322.

[8] CELIK S., The more contagion effect on emerging markets: the evidence of DCC-GARCH model, Econ. Modell., 2012, 29 (5), 1946-1959.

[9] ČERNÝ A., KoBLAS M., Stock market integration and the speed of information transmission. The role of data frequency in cointegration and granger causality tests, J. Int. Bus. Econ., 2005, 1, 110-120.

[10] Chen G.M., FirTh M., Rui O.M., Stock market linkages. Evidence from Latin America, J. Bank. Fin., $2002,26,1113-1141$.

[11] Claessens S., Dornbusch R., Park Y.-C., Contagion. Why crises spread and how this can be stopped, [In:] International Financial Contagion, S. Claessens, K. Forbes (Eds.), Kluwer, Boston 2001, 19-41.

[12] Claessens S., Forbes K. (Eds.), International Financial Contagion, Kluwer, Boston 2001.

[13] CZAPKiewiCZ A., WóJTowicz T., Spatial contagion between stock markets in Central Europe, Manage. Econ., 2017, 18 (1), 23-45.

[14] Dornbusch R., Park Y.-C., Claessens S., Contagion. Understanding how it spreads, World Bank Res. Obs., 2000, 15 (2), 177-197.

[15] Drazen A., Political contagion of currency crises, [In:] P. Krugman (Ed.), Currency Crises, Chicago University Press, Chicago 2000, 47-67.

[16] Dungey M.H., Martin V.L., GonZÁlez-Hermosillo B., Fry R., Transmission of financial crises and contagion. A latent factor approach, Oxford University Press, New York 2010.

[17] Durante F., Foscolo E., An analysis of the dependence among financial markets by spatial contagion, Int. J. Int. Syst., 2013, 28 (4), 319-331.

[18] Durante F., Foscolo E., JaWORSKI P., WANG H., A spatial contagion measure for financial time series, Exp. Syst. Appl., 2014, 41 (8), 4023-4034.

[19] Durante F., Foscolo E., SABo M., A spatial contagion test for financial markets in synergies of soft computing and statistics for intelligent data analysis, [In:] R. Kruse, M. Berthold, C. Moewes, M. Gil, P. Grzegorzewski, O. Hryniewicz (Eds.), Advances in Intelligent Systems and Computing, Springer, Berlin 2013, 313-320.

[20] Durante F., Jaworski P., Spatial contagion between financial markets. A copula-based approach, App. Stoch. Models Bus. Ind., 2010, 26 (5), 551-564.

[21] ÉGERT B., KoČENDA E., Interdependence between Eastern and Western European stock markets. Evidence from intraday data, Econ. Syst., 2007, 31 (2), 184-203.

[22] ÉGERT B., KOČENDA E., Time-varying synchronization of European stock markets, Emp. Econ., 2011, 40 (2), 393-407.

[23] Forbes K., Rigobon R., No contagion, only interdependence. Measuring stock market comovements, J. Fin., 2002, 62 (5), 2223-2261.

[24] Fry-McKibin F., HSiaO Y.-L., Martin V.L., Joint tests of contagion with applications to financial crises, J. Quant. Fin., 2019, 19 (3), 473-490.

[25] Gerlach S., Smets F., Contagious speculative attacks, Eur. J. Pol. Econ., 1995, 11, 5-63. 
[26] Goldstein M., KAminsky G.L., Reinhart C.M., Assessing financial vulnerability. Developing an early warning system for emerging markets, Washington, D.C., Institute for International Economies (https://mpra.ub.uni-muenchen.de/24577/1/MPRA_paper_24577.pdf), 2000.

[27] Gravelle T., Kichian M., Morley J., Detecting shift-contagion in currency and bond markets, J. Int. Econ., 2006, 68 (2), 409-423.

[28] HanOUSEK J., KoČENDA E., KuTAN A.M., The reaction of asset prices to macroeconomic announcements in new EU markets: evidence from intraday data, J. Fin. Stab., 2009, 5 (2), 199-219.

[29] Ho L.C., Huang C.H., Did the contagion effect exist? Evidence from Abu Dhabi, Jordan and America, Econ. Res., 2014, 27 (1), 740-754.

[30] Huynh T.L.D., NAsir M.A., NGuYen S.P., DuOng D., An assessment of contagion risks in the banking system using non-parametric and copula approaches, Econ. Anal. Pol., 2020, 65 (C), 105-116.

[31] JUNG R., MADERITSCH R., Structural breaks in volatility spillovers between international financial markets. Contagion or mere interdependence?, J. Bank. Fin., 2014, 47 (C), 331-342.

[32] KAO Y.S., ZHAO K., KU Y.C., NIEH C.C., The asymmetric contagion effect from the U.S. stock market around the subprime crisis between 2007 and 2010, Econ. Res., 2019, 32 (1), 2422-2454.

[33] Karolyi A.G., Does international finance contagion really exist?, Int. Fin., 2003, 6 (2), 179-199.

[34] Kim S.J., MoshiRian F., Wu E., Dynamic stock market integration driven by the European Monetary Union. An empirical analysis, J. Bank. Fin., 2005, 29, 2475-2502.

[35] LONGIN E., SOLNIK B., Extreme correlation of international equity markets, J. Fin., 2001, 56 (2), 649-676.

[36] Massad N., ANDERSEN J.V., Three different ways synchronization can cause contagion in financial markets, Risks, 2018, 6, 104. DOI:10.3390/risks6040104.

[37] Masson P.R., Multiple equilibria, contagion, and the emerging market crises, IMF Working Paper WP/99/164, International Monetary Fund, 1999.

[38] NiEH C.C., KAO Y.S., YANG C.H., The asymmetric contagion from the U.S. stock market around the subprime crisis, [In:] Studies on Financial Markets in East Asia, Kyushu University Press, Fukuoka 2011.

[39] SavVa C.S., Aslanidis C., Stock market integration between new EU member states and the Eurozone, Emp. Econ., 2010, 39 (2), 337-351.

[40] Syllignakis M.N., KouRETAS G.P., Dynamic correlation analysis of financial contagion: Evidence from the Central and Eastern European markets, Int. Rev. Econ. Fin., 2011, 20 (4), 717-732.

[41] Syriopoulos T., Dynamic linkages between emerging European and developed stock markets. Has the EMU any impact?, Int. Rev. Fin. Anal., 2007, 16 (1), 41-60.

[42] TsE Y.K., TsUi A.K.C., A multivariate generalized autoregressive conditional heteroscedasticity model with time-varying correlations, J. Bus. Econ. Stat., 2002, 20 (3), 351-362.

[43] Voronkova S., Equity market integration in Central European emerging markets. A cointegration analysis with shifting regimes, Int. Rev. Fin. Anal., 2004, 13 (5), 633-647.

[44] WANG H., YUAN Y., Li Y., WANG X., Financial contagion and contagion channels in the forex market: A new approach via the dynamic mixture copula-extreme value theory, Econ. Model., 2021, 94, 401-414.

[45] Wang G.J., XIE C., Tail dependence structure of the foreign exchange market. A network view, Exp. Syst. Appl., 2016, 46, 164-179. 


\section{Appendix}

Table 1. Descriptive statistics for FX returns, 2008 crisis

\begin{tabular}{|c|c|c|c|c|c|c|c|}
\hline & Mean & SD & Median & Min & Max & Skew & Kurtosis \\
\hline \multicolumn{8}{|c|}{1 month before Lehman Brothers bankruptcy } \\
\hline eur_usd & -0.00000608 & 0.00049985 & 0.00000000 & -0.00494118 & 0.00773437 & 0.62 & 29.42 \\
\hline eur_chf & -0.00000207 & 0.00029719 & 0.00000000 & -0.00280126 & 0.00849529 & 4.97 & 145.28 \\
\hline usd_chf & 0.00000400 & 0.00052799 & 0.00000000 & -0.01039473 & 0.00720877 & -0.47 & \\
\hline eur_huf & 0.00000035 & 0.00055152 & 0.00000000 & -0.00818591 & 0.00928344 & 0.41 & 31.55 \\
\hline eur_pln & 0.00000210 & 0.00058198 & 0.00000000 & -0.02050248 & & -7.74 & \\
\hline eur_czk & -0.00000281 & 0.00043977 & 0.00000000 & -0.01377174 & 0.00339065 & -5.96 & \\
\hline usd_czk & 0.00000327 & 0.00065504 & 0.00000000 & -0.01062928 & 0.00490204 & -0.76 & \\
\hline usd huf & 0.00000 & 0.0007 & & -0.012 & & -0.63 & \\
\hline usd pln & 0.000 & 0.0007 & 0.000 & -0.017 & & -2.80 & 71.08 \\
\hline chf_pln & 0.00000 & 0.00065 & 0.0000 & -0.018 & & -6.06 & \\
\hline chf_czk & & & & -0.012 & & -2.87 & \\
\hline chf huf & 0.00000 & 0.0006 & & -0.013 & & -0.83 & \\
\hline pln_czk & -0.0000 & & & & & 0.43 & \\
\hline pln_huf & & & & & & 1.33 & \\
\hline czk huf & 0.00000 & 0.00058183 & 0.00000000 & -0.00556402 & & 0.34 & \\
\hline \multicolumn{8}{|c|}{1 month after Lehman Brothers bankruptcy } \\
\hline & -0.00001023 & 0.00081637 & 0.00000000 & -0.00735026 & 0.01302692 & 0.60 & 16.36 \\
\hline eur_chf & & & & & & 0.11 & \\
\hline usd_chf & 0.000 & 0.000 & & -0.0 & & -0.68 & .47 \\
\hline eur_huf & 0.00001050 & 0.001009 & 0.0000 & -0.00 & 843 & 0.20 & 6.82 \\
\hline & & & & & & -0.08 & \\
\hline eur_czk & & & & & & 0.23 & 13.96 \\
\hline usd_czk & 0.00001407 & & & -0.01303445 & & -0.17 & \\
\hline usd huf & 0.00002 & 0.0013 & 0.000 & -0.01497758 & 191 & -0.11 & 10.26 \\
\hline usd pln & 0.00001652 & 0.0012075 & & -0.01310910 & & -0.23 & 7.96 \\
\hline chf_pln & & & & & & -0.38 & \\
\hline chf_czk & 0.00001080 & 0.0008 & 0.00000206 & -0.00636 & 657 & 0.04 & 6.32 \\
\hline chf huf & 0.00001778 & & & -0.00896635 & & 0.39 & 13.71 \\
\hline & & & & & & 0.25 & \\
\hline pln huf & 0.00000452 & 0.00105991 & -0.00000022 & -0.00978856 & 0.01207763 & 0.34 & 15.25 \\
\hline czk_huf & 0.00000698 & 0.00108425 & 0.00000000 & -0.01251589 & 0.01288236 & 0.29 & \\
\hline \multicolumn{8}{|c|}{3 months before Lehman Brothers bankruptcy } \\
\hline & & 0.00040207 & 0.00000000 & -0.00553191 & 0.00773437 & 0.12 & \\
\hline & -0.00000030 & & & & & 3.10 & \\
\hline usd_chf & 0.00000438 & 0.00046972 & 0.00000000 & -0.01039473 & 0.00720877 & 0.03 & 28.47 \\
\hline eur huf & -0.00000197 & 0.00050023 & 0.00000000 & -0.01608045 & 0.00928344 & -1.91 & \\
\hline eur_pln & -0.00000065 & 0.00042209 & 0.00000000 & -0.02050248 & 0.00924939 & -8.54 & 432.97 \\
\hline eur_czk & -0.00000020 & 0.00039597 & 0.00000000 & -0.01377174 & 0.00413638 & -3.12 & 121.00 \\
\hline usd_czk & 0.00000448 & 0.00055942 & 0.00000000 & -0.01062928 & 0.00490204 & -0.64 & 22.59 \\
\hline
\end{tabular}


Table 1. Descriptive statistics for FX returns, 2008 crisis

\begin{tabular}{|l|c|c|c|c|c|c|c|}
\hline & Mean & SD & Median & Min & Max & Skew & Kurtosis \\
\hline usd_huf & 0.00000270 & 0.00062379 & 0.00000000 & -0.01265391 & 0.00703760 & -0.68 & 25.27 \\
\hline usd_pln & 0.00000403 & 0.00057034 & 0.00000000 & -0.01732268 & 0.00574213 & -2.36 & 81.70 \\
\hline chf_pln & -0.00000034 & 0.00049596 & 0.00000000 & -0.01877252 & 0.00955809 & -6.08 & 230.07 \\
\hline chf_zk & 0.00000010 & 0.00047577 & 0.00000000 & -0.01207912 & 0.00604915 & -1.79 & 55.71 \\
\hline chf_huf & -0.00000168 & 0.00056679 & 0.00000000 & -0.01719062 & 0.01204349 & -2.20 & 99.73 \\
\hline pln_czk & 0.00000045 & 0.00047591 & 0.00000000 & -0.00671898 & 0.00669340 & 0.14 & 17.85 \\
\hline pln_huf & -0.00000133 & 0.00050956 & 0.00000000 & -0.00563937 & 0.01182711 & 0.76 & 29.45 \\
\hline czk_huf & -0.00000178 & 0.00055111 & 0.00000000 & -0.00829816 & 0.00752044 & -0.06 & 17.73 \\
\hline \multicolumn{7}{|c|}{3 months after Lehman Brothers bankruptcy } & \\
\hline eur_usd & -0.00000409 & 0.00085938 & 0.00000000 & -0.00735026 & 0.01302692 & 0.15 & 8.07 \\
\hline eur_chf & -0.00000107 & 0.00059127 & 0.00000000 & -0.00842549 & 0.00525308 & -0.39 & 10.05 \\
\hline usd_chf & 0.00000303 & 0.00076888 & 0.00000834 & -0.01178084 & 0.00700465 & -0.34 & 8.39 \\
\hline eur_huf & 0.00000711 & 0.00122550 & 0.00000000 & -0.02395967 & 0.01674333 & -0.85 & 32.26 \\
\hline eur_pln & 0.00001034 & 0.00111744 & 0.00000000 & -0.01430661 & 0.00902162 & -0.28 & 10.70 \\
\hline eur_czk & 0.00000487 & 0.00075128 & 0.00000000 & -0.01086734 & 0.00844754 & -0.38 & 17.83 \\
\hline usd_czk & 0.00000903 & 0.00118100 & 0.00000000 & -0.01303445 & 0.00992532 & -0.17 & 6.41 \\
\hline usd_huf & 0.00001115 & 0.00149850 & 0.00000505 & -0.02260555 & 0.01244191 & -0.52 & 13.57 \\
\hline usd_pln & 0.00001443 & 0.00142195 & 0.00002167 & -0.01492504 & 0.00987497 & -0.20 & 6.72 \\
\hline chf_pln & 0.00001140 & 0.00126260 & 0.00000746 & -0.01429029 & 0.00924133 & -0.24 & 8.66 \\
\hline chf_czk & 0.00000600 & 0.00099293 & 0.00000213 & -0.01151519 & 0.00934484 & -0.17 & 9.12 \\
\hline chf huf & 0.00000812 & 0.00135530 & 0.00000648 & -0.02484332 & 0.01345738 & -0.63 & 21.94 \\
\hline pln_czk & -0.00000540 & 0.00121219 & -0.00000008 & -0.00973761 & 0.01217621 & 0.14 & 8.06 \\
\hline pln_huf & -0.00000328 & 0.00134469 & 0.00000000 & -0.02568932 & 0.01388641 & -0.41 & 19.02 \\
\hline czk_huf & 0.00000212 & 0.00128353 & 0.00000004 & -0.02223419 & 0.01288236 & -0.32 & 17.80 \\
\hline
\end{tabular}

Table 2. Descriptive statistics for FX returns, Covid-19 crisis

\begin{tabular}{|l|c|c|c|c|c|c|c|}
\hline & Mean & SD & Median & Min & Max & Skew & Kurtosis \\
\hline \multicolumn{9}{|c|}{1 month before Covid-19 recession } \\
\hline eur_usd & -0.00000426 & 0.00015658 & 0.00000000 & -0.00147156 & 0.00168478 & -0.13 & 9.16 \\
\hline eur_chf & -0.00000166 & 0.00015872 & 0.00000000 & -0.00106172 & 0.00258348 & 0.69 & 14.32 \\
\hline usd_chf & 0.00000258 & 0.00019126 & 0.00000000 & -0.00155853 & 0.00251355 & 0.30 & 8.28 \\
\hline eur_huf & 0.00000037 & 0.00020957 & 0.00000000 & -0.00294288 & 0.00260854 & 0.18 & 24.10 \\
\hline eur_pln & 0.00000101 & 0.00015730 & 0.00000000 & -0.00098923 & 0.00111852 & 0.23 & 7.26 \\
\hline eur_czk & -0.00000121 & 0.00016440 & 0.00000000 & -0.00545447 & 0.00119988 & -6.19 & 206.07 \\
\hline usd_czk & 0.00000303 & 0.00022636 & 0.00000044 & -0.00545852 & 0.00152919 & -2.34 & 60.75 \\
\hline usd_huf & 0.00000462 & 0.00026466 & 0.00000000 & -0.00311338 & 0.00257108 & 0.25 & 12.52 \\
\hline usd_pln & 0.00000528 & 0.00022101 & 0.00000257 & -0.00175206 & 0.00152983 & 0.00 & 5.92 \\
\hline chf_pln & 0.00000269 & 0.00023120 & 0.00000261 & -0.00233562 & 0.00155621 & -0.07 & 5.13 \\
\hline chf_czk & 0.00000045 & 0.00023527 & 0.00000180 & -0.00518128 & 0.00155531 & -2.03 & 44.56 \\
\hline chf_huf & 0.00000204 & 0.00027500 & -0.00000053 & -0.00297002 & 0.00265258 & 0.06 & 12.31 \\
\hline pln_czk & -0.00000225 & 0.00021177 & 0.00000068 & -0.00495610 & 0.00140864 & -2.30 & 53.78 \\
\hline
\end{tabular}


Table 2. Descriptive statistics for FX returns, Covid-19 crisis

\begin{tabular}{|c|c|c|c|c|c|c|c|}
\hline & Mean & SD & Median & Min & Max & Skew & Kurtosis \\
\hline pln huf & -0.00000066 & 0.00023314 & -0.00000079 & -0.00320803 & 0.00225694 & -0.39 & 15.88 \\
\hline czk_huf & 0.00000159 & 0.00025713 & -0.00000182 & -0.00298477 & 0.00541278 & 1.78 & 44.05 \\
\hline \multicolumn{8}{|c|}{1 month after Covid-19 recession } \\
\hline eur_usd & -0.00000248 & 0.00055328 & 0.00000000 & -0.00417841 & 0.00600839 & 0.50 & 12.80 \\
\hline eur_chf & -0.00000163 & 0.00031388 & 0.00000000 & -0.00217447 & 0.00326307 & 0.54 & 8.52 \\
\hline usd chf & 0.00000083 & 0.00055589 & 0.00000000 & -0.00644078 & 0.00464208 & -0.12 & 11.48 \\
\hline eur huf & 0.00001034 & 0.00048958 & 0.00000000 & -0.00794175 & 0.00746568 & 0.56 & 37.18 \\
\hline eur_pln & 0.00001168 & 0.00049155 & 0.00000227 & -0.01360991 & 0.00540400 & -3.08 & 116.75 \\
\hline eur_czk & 0.00001835 & 0.00053657 & 0.00000120 & -0.00593394 & 0.00782237 & 1.78 & 41.64 \\
\hline usd_czk & 0.00002084 & 0.00076398 & 0.00000494 & -0.00691893 & 0.00849284 & 0.52 & 14.13 \\
\hline usd huf & 0.00001244 & 0.00074165 & 0.00000000 & -0.00768161 & 0.00691063 & 0.27 & 13.20 \\
\hline usd_pln & 0.00001449 & 0.00071922 & 0.00000260 & -0.0065 & 0.00617984 & -0.13 & 11.45 \\
\hline chf_pln & 0.000013 & 0.00058128 & 0.00000 & -0.006 & 0.0061 & -0.03 & 13.56 \\
\hline chf_czk & 0.00002001 & 0.00063969 & 0.00001478 & -0.00580048 & 0.00797171 & 1.00 & 20.65 \\
\hline chf_huf & 0.00001 & 0.00060814 & 0.00000 & -0.0076 & 0.0087 & 0.43 & 22.33 \\
\hline pln_czk & 0.00000635 & 0.00067092 & 0.00000012 & -0.00 & 0.007 & 0.76 & 22.05 \\
\hline pln_huf & -0.00000205 & 0.00061616 & -0.00000369 & -0.0067 & 0.0070 & 0.06 & 19.33 \\
\hline czk_huf & -0.00000840 & 0.00071181 & -0.00000462 & -0.00956555 & 0.0101 & -0.65 & 32.06 \\
\hline \multicolumn{8}{|c|}{3 months before Covid-19 recession } \\
\hline eur_usd & -0.00000263 & 0.00015954 & 0.00000000 & -0.00147156 & 0.00168478 & 0.08 & 8.02 \\
\hline eur_chf & -0.00000212 & 0.00016493 & 0.00000000 & -0.0010 & 0.0025 & 0.26 & 8.53 \\
\hline usd_chf & 0.00000050 & 0.00019808 & 0.00000000 & -0.00233580 & 0.0025 & -0.09 & 8.24 \\
\hline eur huf & 0.00000171 & 0.00020050 & 0.00000000 & -0.00294288 & 0.00275816 & 0.24 & 25.43 \\
\hline eur_pln & 0.00000009 & 0.00015787 & 0.00000000 & -0.00173 & 0.00201935 & 0.19 & 10.75 \\
\hline eur_czk & -0.00000163 & 0.00015919 & 0.00000000 & -0.00545447 & 0.00176623 & -3.84 & 144.83 \\
\hline usd_czk & 0.00000101 & 0.00022358 & 0.00000044 & -0.00545852 & 0.00198964 & -1.49 & 39.88 \\
\hline usd huf & 0.00000437 & 0.00025902 & 0.00000000 & -0.00311338 & 0.00257108 & 0.06 & 11.27 \\
\hline usd_pln & 0.00000272 & 0.00022606 & 0.00000000 & -0.00206929 & 0.00201259 & -0.11 & 6.52 \\
\hline chf_pln & 0.00000222 & 0.00023728 & 0.00000170 & -0.00233562 & 0.00225674 & 0.02 & 5.98 \\
\hline chf_czk & 0.00000051 & 0.00023607 & 0.00000075 & -0.00518128 & 0.00262428 & -0.90 & 29.75 \\
\hline chf huf & 0.00000387 & 0.00026963 & 0.00000125 & -0.00297002 & 0.00265258 & 0.09 & 11.12 \\
\hline pln_czk & -0.00000171 & 0.00021128 & 0.00000092 & -0.00495610 & 0.00201830 & -1.29 & 36.27 \\
\hline pln_huf & 0.00000166 & 0.00022831 & -0.00000001 & -0.00320803 & 0.00265781 & -0.19 & 15.30 \\
\hline czk_huf & 0.00000337 & 0.00024721 & 0.00000026 & -0.00298477 & 0.00541278 & 1.24 & 36.16 \\
\hline \multicolumn{8}{|c|}{3 months after Covid-19 recession } \\
\hline eur_usd & 0.00000063 & 0.00045699 & 0.00000000 & -0.00417841 & 0.00600839 & 0.43 & 13.08 \\
\hline eur_chf & -0.00000011 & 0.00023827 & 0.00000000 & -0.00217447 & 0.00331176 & 0.74 & 13.87 \\
\hline usd_chf & -0.00000074 & 0.00043483 & 0.00000000 & -0.00644078 & 0.00464208 & -0.20 & 13.52 \\
\hline eur_huf & 0.00000223 & 0.00048060 & 0.00000000 & -0.00802204 & 0.01088819 & 0.24 & 44.72 \\
\hline eur_pln & 0.00000363 & 0.00043586 & 0.00000000 & -0.01360991 & 0.00728989 & -1.47 & 78.90 \\
\hline eur_czk & 0.00000553 & 0.00051831 & 0.00000000 & -0.01361816 & 0.01252099 & 1.00 & 89.22 \\
\hline usd_czk & 0.00000491 & 0.00068702 & 0.00000157 & -0.01342469 & 0.01252718 & 0.19 & 28.25 \\
\hline
\end{tabular}


Table 2. Descriptive statistics for FX returns, Covid-19 crisis

\begin{tabular}{|l|c|c|c|c|c|c|c|}
\hline & Mean & SD & Median & Min & Max & Skew & Kurtosis \\
\hline usd_huf & 0.00000160 & 0.00067494 & 0.00000000 & -0.00768161 & 0.01070423 & 0.06 & 16.21 \\
\hline usd_pln & 0.00000300 & 0.00063445 & 0.00000235 & -0.00673883 & 0.00617984 & -0.33 & 12.27 \\
\hline chf_pln & 0.00000374 & 0.00050536 & 0.00000235 & -0.00645172 & 0.00613934 & -0.19 & 16.17 \\
\hline chf_czk & 0.00000565 & 0.00057652 & 0.00000574 & -0.01148894 & 0.01053587 & 0.68 & 39.57 \\
\hline chf_huf & 0.00000234 & 0.00055474 & 0.00000216 & -0.00768161 & 0.01032530 & 0.19 & 26.34 \\
\hline pln_czk & 0.00000191 & 0.00064262 & 0.00000092 & -0.01404529 & 0.01253199 & 0.36 & 39.69 \\
\hline pln_huf & -0.00000140 & 0.00059910 & -0.00000212 & -0.00742255 & 0.00865619 & -0.07 & 20.29 \\
\hline czk_huf & -0.00000332 & 0.00069132 & -0.00000198 & -0.01530441 & 0.01335689 & -0.80 & 49.50 \\
\hline
\end{tabular}

Table 3. Descriptive statistics for equity indexes returns, 2008 crisis

\begin{tabular}{|c|c|c|c|c|c|c|c|}
\hline & Mean & SD & Median & Min & Max & Skew & Kurtosis \\
\hline \multicolumn{8}{|c|}{1 month before Lehman Brothers bankruptcy } \\
\hline DE30 & -0.0000680 & 0.0020391 & 0.0013405 & -0.0149035 & 0.0096724 & -0.99 & 11.02 \\
\hline NL25 & -0.0000661 & 0.0021613 & 0.0014414 & -0.0198267 & 0.0180184 & -0.44 & 21.34 \\
\hline FR40 & -0.0000620 & 0.0023270 & 0.0016368 & -0.0189282 & 0.0217958 & 0.41 & 21.87 \\
\hline EU50 & -0.0000495 & 0.0020965 & 0.0015468 & -0.0172699 & 0.0170524 & 0.29 & 19.94 \\
\hline UK100 & -0.0000502 & 0.0023519 & 0.0015914 & -0.0149237 & 0.0241077 & 1.37 & 23.61 \\
\hline AU200 & -0.0000361 & 0.0029864 & 0.0012291 & -0.0234685 & 0.0411353 & 3.63 & 75.39 \\
\hline SPX500 & -0.0000798 & 0.0021073 & 0.0012025 & -0.0131545 & 0.0227588 & 1.59 & 31.45 \\
\hline NAS100 & -0.0001804 & 0.0023392 & 0.0013868 & -0.0261169 & 0.0135948 & -3.47 & 36.83 \\
\hline US2000 & -0.0000881 & 0.0024247 & 0.0014399 & -0.0150030 & 0.0243993 & 1.46 & 22.47 \\
\hline JP225 & -0.0001062 & 0.0023592 & 0.0011884 & -0.0176916 & 0.0215255 & -0.05 & 25.99 \\
\hline \multicolumn{8}{|c|}{1 month after Lehman Brothers bankruptcy } \\
\hline DE30 & -0.0001516 & 0.0059134 & 0.0021500 & -0.0990233 & 0.0723462 & -3.45 & 124.25 \\
\hline NL25 & -0.0003043 & 0.0068704 & 0.0026631 & -0.1034255 & 0.0883175 & -3.52 & 110.25 \\
\hline FR40 & -0.0001410 & 0.0063021 & 0.0024655 & -0.0945619 & 0.0829859 & -0.36 & 112.06 \\
\hline EU50 & -0.0001635 & 0.0061214 & & -0.0987604 & 0.0829131 & -2.63 & 127.84 \\
\hline UK100 & -0.0001782 & 0.0064903 & 0.0024874 & -0.0925343 & 0.0859700 & -0.82 & 107.00 \\
\hline AU200 & -0.0001224 & 0.0050747 & 0.0021679 & -0.0485124 & 0.0838579 & 4.64 & 105.09 \\
\hline SPX500 & -0.0001660 & 0.0065814 & 0.0022730 & -0.1014640 & 0.0942627 & -0.26 & 121.84 \\
\hline NAS100 & -0.0001803 & 0.0067308 & 0.0022234 & -0.1030125 & 0.0995723 & 0.51 & 123.55 \\
\hline US2000 & -0.0001884 & 0.0070901 & 0.0022718 & -0.1081517 & 0.0964380 & -1.17 & 122.04 \\
\hline JP225 & -0.0002047 & 0.0072239 & 0.0022499 & -0.1080208 & 0.1099259 & -1.11 & 129.95 \\
\hline \multicolumn{8}{|c|}{3 months before Lehman Brothers bankruptcy } \\
\hline DE30 & -0.0000345 & 0.0020652 & 0.0013698 & -0.0209392 & 0.0157870 & -1.20 & 17.49 \\
\hline NL25 & -0.0000647 & 0.0022396 & 0.0015090 & -0.0294076 & 0.0180184 & -1.48 & 25.70 \\
\hline FR40 & -0.0000394 & 0.0022497 & 0.0014993 & -0.0235157 & 0.0217958 & -0.62 & 23.60 \\
\hline EU50 & -0.0000268 & 0.0020935 & 0.0015373 & -0.0185664 & 0.0175261 & -0.32 & 17.70 \\
\hline UK100 & -0.0000349 & 0.0021688 & 0.0015123 & -0.0225937 & 0.0241077 & 0.09 & 21.10 \\
\hline AU200 & -0.0000459 & 0.0025119 & 0.0011904 & -0.0251581 & 0.0411353 & 0.68 & 62.12 \\
\hline
\end{tabular}


Table 3. Descriptive statistics for equity indexes returns, 2008 crisis

\begin{tabular}{|l|c|c|c|c|c|c|c|}
\hline & Mean & SD & Median & Min & Max & Skew & Kurtosis \\
\hline SPX500 & -0.0000383 & 0.0019655 & 0.0011654 & -0.0215543 & 0.0227588 & -0.22 & 31.01 \\
\hline NAS100 & -0.0000434 & 0.0022887 & 0.0013268 & -0.0261169 & 0.0244915 & -0.83 & 25.77 \\
\hline US2000 & -0.0000081 & 0.0023199 & 0.0013366 & -0.0251986 & 0.0268128 & 1.10 & 28.58 \\
\hline JP225 & -0.0000605 & 0.0023640 & 0.0011394 & -0.0331492 & 0.0215255 & -2.82 & 50.64 \\
\hline \multicolumn{7}{|c|}{ 3 months after Lehman Brothers bankruptcy } \\
\hline DE30 & -0.0000915 & 0.0056089 & 0.0030715 & -0.0990233 & 0.0723462 & -2.60 & 85.54 \\
\hline NL25 & -0.0001535 & 0.0060598 & 0.0031793 & -0.1034255 & 0.0883175 & -2.44 & 89.05 \\
\hline FR40 & -0.0000918 & 0.0057045 & 0.0030444 & -0.0945619 & 0.0829859 & -1.10 & 86.01 \\
\hline EU50 & -0.0000971 & 0.0055786 & 0.0028233 & -0.0987604 & 0.0829131 & -2.89 & 104.82 \\
\hline UK100 & -0.0000675 & 0.0056825 & 0.0028481 & -0.0954824 & 0.0859700 & -1.82 & 103.02 \\
\hline AU200 & -0.0001049 & 0.0046067 & 0.0024597 & -0.0485124 & 0.0838579 & 1.49 & 68.41 \\
\hline SPX500 & -0.0001120 & 0.0057877 & 0.0026370 & -0.1014640 & 0.0942627 & -1.69 & 103.79 \\
\hline NAS100 & -0.0001286 & 0.0061215 & 0.0026523 & -0.1030125 & 0.0995723 & -1.47 & 109.66 \\
\hline US2000 & -0.0001481 & 0.0066229 & 0.0029087 & -0.1102055 & 0.0964380 & -2.75 & 105.62 \\
\hline JP225 & -0.0001194 & 0.0070649 & 0.0026579 & -0.1627468 & 0.1099259 & -4.22 & 166.22 \\
\hline
\end{tabular}

Table 4. Descriptive statistics for equity indexes returns, Covid-19 crisis

\begin{tabular}{|l|c|c|c|c|c|c|c|}
\hline & Mean & SD & Median & Min & Max & Skew & Kurtosis \\
\hline \multicolumn{7}{|c|}{1 month before Covid-19 recession } \\
\hline DE30 & 0.0000061 & 0.0007179 & 0.0004587 & -0.0102100 & 0.0078108 & -0.71 & 36.89 \\
\hline NL25 & 0.0000070 & 0.0006939 & 0.0004133 & -0.0084873 & 0.0065877 & -0.93 & 28.78 \\
\hline FR40 & 0.0000003 & 0.0007325 & 0.0004934 & -0.0101905 & 0.0070869 & -1.05 & 34.32 \\
\hline EU50 & 0.0000046 & 0.0007145 & 0.0004004 & -0.0089749 & 0.0068274 & -0.85 & 28.78 \\
\hline UK100 & -0.0000091 & 0.0006998 & 0.0004982 & -0.0075846 & 0.0076823 & -0.17 & 22.36 \\
\hline AU200 & 0.0000027 & 0.0005434 & 0.0004156 & -0.0057347 & 0.0093454 & 0.87 & 46.50 \\
\hline SPX500 & 0.0000064 & 0.0006562 & 0.0004373 & -0.0113497 & 0.0070745 & -1.61 & 58.65 \\
\hline NAS100 & 0.0000205 & 0.0008740 & 0.0004954 & -0.0128949 & 0.0130330 & -0.79 & 63.22 \\
\hline US2000 & -0.0000003 & 0.0007930 & 0.0004911 & -0.0105444 & 0.0064459 & -0.78 & 22.38 \\
\hline JP225 & -0.0000052 & 0.0008745 & 0.0004750 & -0.0169471 & 0.0086441 & -3.16 & 98.38 \\
\hline \multicolumn{7}{|c|}{11 month after Covid-19 recession } \\
\hline DE30 & -0.0001622 & 0.0047958 & 0.0018708 & -0.1420368 & 0.0479605 & -11.39 & 311.34 \\
\hline NL25 & -0.0001376 & 0.0046478 & 0.0019031 & -0.1361833 & 0.0476130 & -10.77 & 299.52 \\
\hline FR40 & -0.0001596 & 0.0050098 & 0.0019226 & -0.1574681 & 0.0512432 & -12.77 & 378.11 \\
\hline EU50 & -0.0001564 & 0.0049919 & 0.0020030 & -0.1473088 & 0.0510682 & -11.11 & 308.14 \\
\hline UK100 & -0.0001280 & 0.0045415 & 0.0016953 & -0.1396660 & 0.0551872 & -12.43 & 362.45 \\
\hline AU200 & -0.0001256 & 0.0060048 & 0.0015666 & -0.1592407 & 0.1043549 & -6.81 & 328.57 \\
\hline SPX500 & -0.0001177 & 0.0045588 & 0.0019382 & -0.1143734 & 0.0449505 & -6.94 & 168.55 \\
\hline NAS100 & -0.0001004 & 0.0045675 & 0.0021598 & -0.1112995 & 0.0489067 & -5.81 & 146.14 \\
\hline US2000 & -0.0001674 & 0.0052377 & 0.0019927 & -0.1391999 & 0.0378229 & -7.62 & 190.18 \\
\hline JP225 & -0.0001046 & 0.0042267 & 0.0016133 & -0.1141285 & 0.0519638 & -9.56 & 257.90 \\
\hline
\end{tabular}


Table 4. Descriptive statistics for equity indexes returns, Covid-19 crisis

\begin{tabular}{|l|c|c|c|c|c|c|c|}
\hline & Mean & SD & Median & Min & Max & Skew & Kurtosis \\
\hline \multicolumn{7}{|c|}{3 months before Covid-19 recession } \\
\hline DE30 & 0.0000081 & 0.0007088 & 0.0004486 & -0.0102100 & 0.0078108 & -0.77 & 35.94 \\
\hline NL25 & 0.0000073 & 0.0006421 & 0.0003805 & -0.0084873 & 0.0065877 & -0.82 & 28.46 \\
\hline FR40 & 0.0000043 & 0.0006856 & 0.0004637 & -0.0101905 & 0.0074429 & -0.97 & 34.90 \\
\hline EU50 & 0.0000060 & 0.0006842 & 0.0003950 & -0.0089749 & 0.0071395 & -0.92 & 30.48 \\
\hline UK100 & -0.0000029 & 0.0006379 & 0.0004617 & -0.0075846 & 0.0076823 & -0.26 & 22.21 \\
\hline AU200 & 0.0000097 & 0.0005381 & 0.0003254 & -0.0057347 & 0.0093454 & 2.00 & 55.58 \\
\hline SPX500 & 0.0000109 & 0.0005883 & 0.0003554 & -0.0113497 & 0.0070745 & -1.07 & 61.88 \\
\hline NAS100 & 0.0000234 & 0.0007903 & 0.0004216 & -0.0128949 & 0.0130330 & -0.16 & 67.46 \\
\hline US2000 & 0.0000034 & 0.0007410 & 0.0004447 & -0.0105444 & 0.0064459 & -0.64 & 20.43 \\
\hline JP225 & -0.0000015 & 0.0007955 & 0.0003237 & -0.0169471 & 0.0086441 & -3.30 & 106.52 \\
\hline \multicolumn{7}{|c|}{3 months after Covid-19 recession } \\
\hline DE30 & -0.0000260 & 0.0033203 & 0.0014621 & -0.1420368 & 0.0479605 & -10.79 & 460.83 \\
\hline NL25 & -0.0000227 & 0.0031791 & 0.0013742 & -0.1361833 & 0.0476130 & -10.58 & 464.52 \\
\hline FR40 & -0.0000369 & 0.0034226 & 0.0015229 & -0.1574681 & 0.0512432 & -12.82 & 583.32 \\
\hline EU50 & -0.0000337 & 0.0034065 & 0.0015584 & -0.1473088 & 0.0510682 & -11.21 & 479.10 \\
\hline UK100 & -0.0000264 & 0.0031374 & 0.0013526 & -0.1396660 & 0.0551872 & -12.06 & 535.23 \\
\hline AU200 & -0.0000302 & 0.0040804 & 0.0012632 & -0.1592407 & 0.1043549 & -7.12 & 539.51 \\
\hline SPX500 & -0.0000169 & 0.0032768 & 0.0014683 & -0.1143734 & 0.0510759 & -5.79 & 225.13 \\
\hline NAS100 & -0.0000052 & 0.0032711 & 0.0014937 & -0.1112995 & 0.0537568 & -4.70 & 201.50 \\
\hline US2000 & -0.0000297 & 0.0040690 & 0.0019536 & -0.1391999 & 0.0624415 & -5.18 & 192.54 \\
\hline JP225 & -0.0000169 & 0.0030565 & 0.0011497 & -0.1141285 & 0.0671667 & -7.17 & 364.04 \\
\hline
\end{tabular}

Table 5. Descriptive statistics for FX volatility, 2008 crisis

\begin{tabular}{|l|c|c|c|c|c|c|c|}
\hline & Mean & SD & Median & Min & Max & Skew & Kurtosis \\
\hline \multicolumn{7}{|c|}{1 month before Lehman Brothers bankruptcy } \\
\hline eur_usd & 0.00000025 & 0.00000140 & 0.00000005 & 0.00000000 & 0.00005982 & 32.19 & 1275.49 \\
\hline eur_chf & 0.00000009 & 0.00000107 & 0.00000001 & 0.00000000 & 0.00007217 & 60.22 & 3949.82 \\
\hline usd_chf & 0.00000028 & 0.00000182 & 0.00000006 & 0.00000000 & 0.00010805 & 45.07 & 2478.58 \\
\hline eur_huf & 0.00000030 & 0.00000176 & 0.00000002 & 0.00000000 & 0.00008618 & 33.76 & 1475.61 \\
\hline eur_pln & 0.00000034 & 0.00000599 & 0.00000001 & 0.00000000 & 0.00042035 & 66.51 & 4631.03 \\
\hline eur_czk & 0.00000019 & 0.00000268 & 0.00000001 & 0.00000000 & 0.00018966 & 67.36 & 4748.79 \\
\hline usd_czk & 0.00000043 & 0.00000207 & 0.00000008 & 0.00000000 & 0.00011298 & 35.21 & 1748.69 \\
\hline usd_huf & 0.00000056 & 0.00000273 & 0.00000010 & 0.00000000 & 0.00016012 & 40.30 & 2255.60 \\
\hline usd_pln & 0.00000058 & 0.00000500 & 0.00000009 & 0.00000000 & 0.00030008 & 49.16 & 2729.78 \\
\hline chf_pln & 0.00000043 & 0.00000589 & 0.00000004 & 0.00000000 & 0.00035241 & 49.13 & 2692.43 \\
\hline chf_czk & 0.00000027 & 0.00000238 & 0.00000003 & 0.00000000 & 0.00014591 & 48.56 & 2787.53 \\
\hline chf_huf & 0.00000042 & 0.00000352 & 0.00000004 & 0.00000000 & 0.00018428 & 41.54 & 1977.38 \\
\hline pln_czk & 0.00000030 & 0.00000123 & 0.00000002 & 0.00000000 & 0.00004480 & 18.26 & 523.79 \\
\hline pln_huf & 0.00000036 & 0.00000215 & 0.00000003 & 0.00000000 & 0.00013988 & 52.73 & 3379.46 \\
\hline czk_huf & 0.00000034 & 0.00000118 & 0.00000002 & 0.00000000 & 0.00003593 & 13.67 & 306.95 \\
\hline
\end{tabular}


Table 5. Descriptive statistics for FX volatility, 2008 crisis

\begin{tabular}{|c|c|c|c|c|c|c|c|}
\hline & Mean & SD & Median & Min & Max & Skew & Kurtosis \\
\hline \multicolumn{8}{|c|}{1 month after Lehman Brothers bankruptcy } \\
\hline eur_usd & 0.00000067 & 0.00000285 & 0.00000019 & 0.00000000 & 0.00016970 & 41.47 & 2314.70 \\
\hline eur_chf & 0.00000026 & 0.00000069 & 0.00000006 & 0.00000000 & 0.00001757 & 8.89 & 129.92 \\
\hline usd_chf & 0.00000064 & 0.00000251 & 0.00000018 & 0.00000000 & 0.00013879 & 35.54 & 1784.27 \\
\hline eur huf & 0.00000102 & 0.00000443 & 0.00000005 & 0.00000000 & 0.00011275 & 14.44 & 292.58 \\
\hline eur_pln & 0.00000086 & 0.00000331 & 0.00000007 & 0.00000000 & 0.00009240 & 12.86 & 247.09 \\
\hline eur_czk & 0.00000044 & 0.00000174 & 0.00000001 & 0.00000000 & 0.00007136 & 17.30 & 551.81 \\
\hline usd_czk & 0.00000114 & 0.00000369 & 0.00000028 & 0.00000000 & 0.00016990 & 22.36 & 865.35 \\
\hline usd huf & 0.00000173 & 0.00000604 & 0.00000034 & 0.00000000 & 0.00022433 & 16.68 & 461.95 \\
\hline usd_pln & 0.00000146 & 0.00000460 & 0.00000031 & 0.00000000 & 0.00017185 & 15.91 & 439.66 \\
\hline chf_pln & 0.00000107 & 0.00000379 & 0.00000017 & 0.00000000 & 0.00014969 & 16.75 & 498.01 \\
\hline chf_czk & 0.00000073 & 0.00000210 & 0.00000014 & 0.00000000 & 0.00005471 & 9.90 & 160.21 \\
\hline chf_huf & 0.00000131 & 0.00000521 & 0.00000017 & 0.00000000 & 0.00018110 & 16.06 & 403.11 \\
\hline pln_czk & 0.00000099 & 0.00000367 & 0.00000009 & 0.00000000 & & 16.14 & 439.58 \\
\hline pln_huf & 0.00000112 & 0.00000467 & 0.00000010 & 0.00000000 & 0.00014587 & 15.76 & 358.64 \\
\hline czk_huf & 0.00000118 & 0.00000490 & 0.00000009 & 0.00000000 & 0.00016596 & 18.34 & 502.10 \\
\hline \multicolumn{8}{|c|}{3 months before Lehman Brothers bankruptcy } \\
\hline eur usd & 0.00000016 & 0.00000090 & 0.00000003 & 0.00000000 & 0.00005982 & 44.25 & 2633.48 \\
\hline eur_chf & 0.00000006 & 0.00000064 & 0.00000001 & 0.00000000 & & 97.04 & 10645.29 \\
\hline usd chf & 0.00000022 & 0.00000122 & 0.00000004 & 0.00000000 & 0.00010805 & 55.54 & 4351.39 \\
\hline eur huf & 0.00000025 & 0.00000245 & 0.00000001 & 0.00000000 & 0.00025858 & 81.28 & 8144.81 \\
\hline eur pln & 0.00000018 & 0.00000372 & 0.00000001 & 0.00000000 & 0.00042035 & 99.47 & 10838.27 \\
\hline eur_czk & 0.00000016 & 0.00000174 & 0.00000000 & 0.00000000 & 0.00018966 & 87.51 & 9259.67 \\
\hline usd_czk & 0.00000031 & 0.00000155 & 0.00000004 & 0.00000000 & 0.00011298 & 36.75 & 2156.47 \\
\hline usd huf & 0.00000039 & 0.00000203 & 0.00000006 & 0.00000000 & 0.00016012 & 45.83 & 3099.79 \\
\hline usd_pln & 0.00000033 & 0.00000297 & 0.00000005 & 0.00000000 & 0.00030008 & 79.96 & 7448.04 \\
\hline chf_pln & 0.00000025 & 0.00000375 & 0.00000003 & 0.00000000 & 0.00035241 & 72.29 & 5955.04 \\
\hline chf_czk & 0.00000023 & 0.00000172 & 0.00000003 & 0.00000000 & 0.00014591 & 52.64 & 3822.88 \\
\hline chf_huf & 0.00000032 & 0.00000324 & 0.00000003 & 0.00000000 & 0.00029552 & 67.69 & 5419.96 \\
\hline pln_czk & 0.00000023 & 0.00000101 & 0.00000001 & & & 20.66 & \\
\hline pln huf & 0.00000026 & 0.00000146 & 0.00000002 & 0.00000000 & 0.00013988 & 62.44 & 5628.07 \\
\hline czk_huf & 0.00000030 & 0.00000135 & 0.00000001 & 0.00000000 & 0.00006886 & 23.57 & 877.37 \\
\hline \multicolumn{8}{|c|}{3 months after Lehman Brothers bankruptcy } \\
\hline eur_usd & 0.00000074 & 0.00000234 & 0.00000021 & 0.00000000 & 0.00016970 & 31.24 & 1875.11 \\
\hline eur_chf & 0.00000035 & 0.00000121 & 0.00000008 & 0.00000000 & 0.00007099 & 23.81 & 1010.99 \\
\hline usd_chf & 0.00000059 & 0.00000191 & 0.00000016 & 0.00000000 & 0.00013879 & 31.18 & 1896.54 \\
\hline eur huf & 0.00000150 & 0.00000879 & 0.00000004 & 0.00000000 & 0.00057407 & 35.19 & 1903.56 \\
\hline eur_pln & 0.00000125 & 0.00000445 & 0.00000008 & 0.00000000 & 0.00020468 & 13.92 & 392.06 \\
\hline eur_czk & 0.00000056 & 0.00000251 & 0.00000001 & 0.00000000 & 0.00011810 & 18.35 & 564.63 \\
\hline usd_czk & 0.00000139 & 0.00000404 & 0.00000031 & 0.00000000 & 0.00016990 & 14.69 & 412.39 \\
\hline usd_huf & 0.00000225 & 0.00000886 & 0.00000040 & 0.00000000 & 0.00051101 & 24.99 & 1076.85 \\
\hline usd_pln & 0.00000202 & 0.00000597 & 0.00000041 & 0.00000000 & 0.00022276 & 12.12 & 267.19 \\
\hline
\end{tabular}


Table 5. Descriptive statistics for FX volatility, 2008 crisis

\begin{tabular}{|l|c|c|c|c|c|c|c|}
\hline & Mean & SD & Median & Min & Max & Skew & Kurtosis \\
\hline chf_pln & 0.00000159 & 0.00000520 & 0.00000023 & 0.00000000 & 0.00020421 & 12.50 & 290.96 \\
\hline chf_czk & 0.00000099 & 0.00000329 & 0.00000017 & 0.00000000 & 0.00013260 & 15.75 & 437.46 \\
\hline chf_huf & 0.00000184 & 0.00000898 & 0.00000022 & 0.00000000 & 0.00061719 & 33.97 & 1898.92 \\
\hline pln_czk & 0.00000147 & 0.00000466 & 0.00000012 & 0.00000000 & 0.00014826 & 10.34 & 190.63 \\
\hline pln_huf & 0.00000181 & 0.00000829 & 0.00000016 & 0.00000000 & 0.00065994 & 38.91 & 2684.91 \\
\hline czk_huf & 0.00000165 & 0.00000733 & 0.00000012 & 0.00000000 & 0.00049436 & 28.54 & 1496.16 \\
\hline
\end{tabular}

Table 6. Descriptive statistics for FX volatility, Covid-19 crisis

\begin{tabular}{|c|c|c|c|c|c|c|c|}
\hline & Mean & SD & Median & Min & Max & Skew & Kurtosis \\
\hline \multicolumn{8}{|c|}{1 month before Covid-19 recession } \\
\hline eur_usd & 0.00000002 & 0.00000008 & 0.00000001 & 0.00000000 & 0.00000284 & 15.68 & 384.63 \\
\hline eur_chf & 0.00000003 & 0.00000010 & 0.00000001 & 0.00000000 & 0.00000667 & 46.54 & 2961.11 \\
\hline usd chf & 0.00000004 & 0.00000012 & 0.00000001 & 0.00000000 & 0.00000632 & 28.07 & 1361.19 \\
\hline eur_huf & 0.00000004 & 0.00000022 & 0.00000000 & 0.00000000 & 0.00000866 & 20.37 & 600.53 \\
\hline eur_pln & 0.00000002 & 0.00000008 & 0.00000000 & 0.00000000 & 0.00000125 & 6.83 & 65.84 \\
\hline eur_czk & 0.00000003 & 0.00000039 & 0.00000000 & 0.00000000 & 0.00002975 & 71.64 & 5444.06 \\
\hline usd_czk & 0.00000005 & 0.00000041 & 0.00000001 & 0.00000000 & 0.00002980 & 64.14 & 4672.33 \\
\hline usd_huf & 0.00000007 & 0.00000027 & 0.00000001 & 0.00000000 & 0.00000969 & 16.67 & 435.55 \\
\hline usd pln & 0.00000005 & 0.00000014 & 0.00000001 & 0.00000000 & 0.00000307 & 9.49 & 144.29 \\
\hline chf_pln & 0.00000005 & 0.00000014 & 0.00000001 & 0.00000000 & 0.00000546 & 12.91 & 364.84 \\
\hline chf czk & 0.00000006 & 0.00000038 & 0.00000001 & 0.00000000 & 0.00002685 & 59.08 & 4107.38 \\
\hline chf_huf & 0.00000008 & 0.00000029 & 0.00000001 & 0.00000000 & 0.00000882 & 15.47 & 348.06 \\
\hline pln_czk & 0.00000004 & 0.00000034 & 0.00000000 & 0.00000000 & 0.00002456 & 63.57 & 4617.53 \\
\hline pln huf & 0.00000005 & 0.00000023 & 0.00000000 & 0.00000000 & 0.00001029 & 21.83 & 758.75 \\
\hline czk huf & 0.00000007 & 0.00000045 & 0.00000000 & 0.00000000 & 0.00002930 & 47.52 & 2942.25 \\
\hline \multicolumn{8}{|c|}{1 month after Covid-19 recession } \\
\hline eur_usd & 0.00000031 & 0.00000118 & 0.00000005 & 0.00000000 & 0.00003610 & 15.89 & 369.83 \\
\hline eur_chf & 0.00000010 & 0.00000032 & 0.00000002 & 0.00000000 & & 13.32 & 305.24 \\
\hline usd_chf & 0.00000031 & 0.00000113 & 0.00000005 & 0.00000000 & 0.00004148 & 16.88 & 444.95 \\
\hline eur huf & 0.00000024 & 0.00000150 & 0.00000001 & 0.00000000 & 0.00006307 & 25.25 & 897.61 \\
\hline eur pln & 0.00000024 & 0.00000263 & 0.00000001 & 0.00000000 & 0.00018523 & 60.55 & 4211.59 \\
\hline eur_czk & 0.00000029 & 0.00000191 & 0.00000001 & 0.00000000 & 0.00006119 & 20.33 & 522.10 \\
\hline usd_czk & 0.00000058 & 0.00000235 & 0.00000007 & 0.00000000 & 0.00007213 & 13.97 & 288.75 \\
\hline usd huf & 0.00000055 & 0.00000215 & 0.00000007 & 0.00000000 & 0.00005901 & 12.80 & 233.13 \\
\hline usd pln & 0.00000052 & 0.00000190 & 0.00000007 & 0.00000000 & 0.00004290 & 11.07 & 173.13 \\
\hline chf_pln & 0.00000034 & 0.00000133 & 0.00000004 & 0.00000000 & 0.00004162 & 14.60 & 330.88 \\
\hline chf_czk & 0.00000041 & 0.00000195 & 0.00000004 & 0.00000000 & 0.00006355 & 17.82 & 426.45 \\
\hline chf_huf & 0.00000037 & 0.00000183 & 0.00000005 & 0.00000000 & 0.00007585 & 22.58 & 745.18 \\
\hline pln_czk & 0.00000045 & 0.00000221 & 0.00000003 & 0.00000000 & 0.00006347 & 14.95 & 303.94 \\
\hline pln_huf & 0.00000038 & 0.00000175 & 0.00000003 & 0.00000000 & 0.00005020 & 14.08 & 285.43 \\
\hline czk_huf & 0.00000051 & 0.00000296 & 0.00000003 & 0.00000000 & 0.00010396 & 20.53 & 558.22 \\
\hline
\end{tabular}


Table 6. Descriptive statistics for FX volatility, Covid-19 crisis

\begin{tabular}{|c|c|c|c|c|c|c|c|}
\hline & Mean & SD & Median & Min & Max & Skew & Kurtosis \\
\hline \multicolumn{8}{|c|}{3 months before Covid-19 recession } \\
\hline eur_usd & 0.00000003 & 0.00000008 & 0.00000001 & 0.00000000 & 0.00000284 & 16.60 & 444.06 \\
\hline eur_chf & 0.00000003 & 0.00000009 & 0.00000001 & 0.00000000 & 0.00000667 & 41.23 & 2943.10 \\
\hline usd_chf & 0.00000004 & 0.00000013 & 0.00000001 & 0.00000000 & 0.00000632 & 23.06 & 936.28 \\
\hline eur huf & 0.00000004 & 0.00000021 & 0.00000000 & 0.00000000 & 0.00000866 & 20.26 & 613.84 \\
\hline eur_pln & 0.00000002 & 0.00000009 & 0.00000000 & 0.00000000 & 0.00000408 & 15.82 & 532.69 \\
\hline eur_czk & 0.00000003 & 0.00000031 & 0.00000000 & 0.00000000 & 0.00002975 & 83.03 & 7951.22 \\
\hline usd_czk & 0.00000005 & 0.00000032 & 0.00000001 & 0.00000000 & 0.00002980 & 71.78 & 6496.84 \\
\hline usd huf & 0.00000007 & 0.00000024 & 0.00000001 & 0.00000000 & 0.00000969 & 15.28 & 389.37 \\
\hline usd_pln & 0.00000005 & 0.00000015 & 0.00000001 & 0.00000000 & 0.00000428 & 11.37 & 218.93 \\
\hline chf_pln & 0.00000006 & 0.00000016 & 0.00000001 & 0.00000000 & 0.00000546 & 13.00 & 317.30 \\
\hline chf_czk & 0.00000006 & 0.00000031 & 0.00000001 & 0.00000000 & 0.00002685 & 59.73 & 4859.28 \\
\hline chf_huf & 0.00000007 & 0.00000026 & 0.00000001 & 0.00000000 & 0.00000882 & 14.56 & 321.60 \\
\hline pln_czk & 0.00000004 & 0.00000028 & 0.00000000 & 0.00000000 & 0.00002456 & 65.04 & 5634.09 \\
\hline pln_huf & 0.00000005 & 0.00000022 & 0.00000000 & 0.00000000 & 0.00001029 & 20.02 & 666.96 \\
\hline czk_huf & 0.00000006 & 0.00000038 & 0.00000000 & 0.00000000 & 0.00002930 & 46.87 & 3322.88 \\
\hline \multicolumn{8}{|c|}{3 months after Covid-19 recession } \\
\hline eur_usd & 0.00000021 & 0.00000081 & 0.00000003 & 0.00000000 & 0.00003610 & 19.29 & 603.09 \\
\hline eur_chf & 0.00000006 & 0.00000023 & & 0.00000000 & & 20.78 & 749.34 \\
\hline usd_chf & 0.00000019 & 0.00000074 & 0.00000003 & 0.00000000 & 0.00004148 & 22.06 & 841.40 \\
\hline eur huf & 0.00000023 & 0.00000158 & 0.00000001 & 0.00000000 & 0.00011855 & 38.07 & 2254.61 \\
\hline eur pln & 0.00000019 & 0.00000171 & 0.00000001 & 0.00000000 & 0.00018523 & 77.02 & 7989.68 \\
\hline eur_czk & 0.00000027 & 0.00000257 & 0.00000001 & 0.00000000 & 0.00018545 & 45.79 & 2722.28 \\
\hline usd_czk & 0.00000047 & 0.00000260 & 0.00000006 & 0.00000000 & 0.00018022 & 38.00 & 2198.11 \\
\hline usd huf & 0.00000046 & 0.00000194 & 0.00000006 & 0.00000000 & 0.00011458 & 21.82 & 875.58 \\
\hline usd pln & 0.00000040 & 0.00000152 & 0.00000006 & 0.00000000 & 0.00004541 & 13.24 & 259.25 \\
\hline chf_pln & 0.00000026 & 0.00000109 & 0.00000003 & 0.00000000 & 0.00004162 & 15.76 & 391.18 \\
\hline chf_czk & 0.00000033 & 0.00000214 & 0.00000003 & 0.00000000 & 0.00013200 & 35.51 & 1752.41 \\
\hline chf_huf & 0.00000031 & 0.00000164 & 0.00000003 & 0.00000000 & 0.00010661 & 30.33 & 1489.05 \\
\hline pln_czk & 0.00000041 & 0.00000267 & 0.00000003 & 0.00000000 & 0.00019727 & 41.01 & 2513.79 \\
\hline pln_huf & 0.00000036 & 0.00000169 & 0.00000003 & 0.00000000 & 0.00007493 & 17.98 & 500.21 \\
\hline czk huf & 0.00000048 & 0.00000343 & 0.00000003 & 0.00000000 & 0.00023422 & 38.81 & 2060.99 \\
\hline
\end{tabular}

Table 7. Descriptive statistics for equity indexes volatility, 2008 crisis

\begin{tabular}{|l|c|c|c|c|c|c|c|}
\hline & Mean & SD & Median & Min & Max & Skew & Kurtosis \\
\hline \multicolumn{8}{|c|}{1 month before Lehman Brothers bankruptcy } \\
\hline DE30 & 0.0000042 & 0.0000151 & 0.0000008 & 0.0000000 & 0.0002221 & 10.05 & 120.80 \\
\hline NL25 & 0.0000047 & 0.0000226 & 0.0000010 & 0.0000000 & 0.0003931 & 13.64 & 208.51 \\
\hline FR40 & 0.0000054 & 0.0000265 & 0.0000011 & 0.0000000 & 0.0004751 & 13.80 & 215.19 \\
\hline EU50 & 0.0000044 & 0.0000206 & 0.0000011 & 0.0000000 & 0.0002982 & 11.60 & 147.69 \\
\hline
\end{tabular}


Table 7. Descriptive statistics for equity indexes volatility, 2008 crisis

\begin{tabular}{|c|c|c|c|c|c|c|c|}
\hline & Mean & SD & Median & Min & Max & Skew & Kurtosis \\
\hline UK100 & 0.0000055 & 0.0000280 & 0.0000012 & 0.0000000 & 0.0005812 & 15.69 & 298.28 \\
\hline AU200 & 0.0000089 & 0.0000784 & 0.0000007 & 0.0000000 & 0.0016921 & 17.36 & 349.11 \\
\hline SPX500 & 0.0000044 & 0.0000256 & 0.0000007 & 0.0000000 & 0.0005180 & 15.22 & 274.90 \\
\hline NAS100 & 0.0000055 & 0.0000346 & 0.0000008 & 0.0000000 & 0.0006821 & 15.40 & 268.63 \\
\hline US2000 & 0.0000059 & 0.0000290 & 0.0000010 & 0.0000000 & 0.0005953 & 15.43 & 287.19 \\
\hline JP225 & 0.0000056 & 0.0000295 & 0.0000006 & 0.0000000 & 0.0004633 & 10.84 & 133.59 \\
\hline \multicolumn{8}{|c|}{1 month after Lehman Brothers bankruptcy } \\
\hline DE30 & 0.0000350 & 0.0003937 & 0.0000021 & 0.0000000 & 0.0098056 & 19.46 & 432.99 \\
\hline NL25 & 0.0000472 & 0.0005018 & 0.0000033 & 0.0000000 & 0.0106968 & 16.33 & 293.26 \\
\hline FR40 & 0.0000397 & 0.0004245 & 0.0000028 & 0.0000000 & 0.0089419 & 16.78 & 302.93 \\
\hline EU50 & 0.0000375 & 0.0004277 & 0.0000026 & 0.0000000 & 0.0097536 & 18.05 & 357.26 \\
\hline UK100 & 0.0000421 & 0.0004402 & 0.0000028 & 0.0000000 & 0.0085626 & 15.51 & 258.17 \\
\hline AU200 & 0.0000257 & 0.0002661 & 0.0000021 & 0.0000000 & 0.0070321 & 21.38 & 520.90 \\
\hline SPX500 & 0.0000433 & 0.0004823 & 0.0000024 & 0.0000000 & 0.0102949 & 17.60 & 336.78 \\
\hline NAS100 & 0.0000453 & 0.0005078 & 0.0000023 & 0.0000000 & 0.0106116 & 17.94 & 347.46 \\
\hline US2000 & 0.0000503 & 0.0005605 & 0.0000023 & 0.0000000 & 0.0116968 & 16.52 & 294.95 \\
\hline JP225 & 0.0000522 & 0.0006001 & 0.0000023 & 0.0000000 & 0.0120837 & 17.42 & 325.29 \\
\hline \multicolumn{8}{|c|}{3 months before Lehman Brothers bankruptcy } \\
\hline DE30 & 0.0000043 & 0.0000189 & 0.0000009 & 0.0000000 & 0.0004385 & 13.15 & 223.66 \\
\hline NL25 & 0.0000050 & 0.0000265 & 0.0000010 & 0.0000000 & 0.0008648 & 19.43 & 519.54 \\
\hline FR40 & 0.0000051 & 0.0000256 & 0.0000010 & 0.0000000 & 0.0005530 & 13.62 & 217.57 \\
\hline EU50 & 0.0000044 & 0.0000195 & 0.0000011 & 0.0000000 & 0.0003447 & 11.78 & 162.61 \\
\hline UK100 & 0.0000047 & 0.0000226 & 0.0000010 & 0.0000000 & 0.0005812 & 16.29 & 332.97 \\
\hline AU200 & 0.0000063 & 0.0000505 & 0.0000006 & 0.0000000 & 0.0016921 & 20.03 & 558.50 \\
\hline SPX500 & 0.0000039 & 0.0000222 & & 0.0000000 & 0.0005180 & 15.46 & 292.36 \\
\hline NAS100 & 0.0000052 & 0.0000276 & 0.0000008 & 0.0000000 & 0.0006821 & 15.55 & 301.93 \\
\hline US2000 & 0.0000054 & 0.0000298 & 0.0000008 & 0.0000000 & 0.0007189 & 16.17 & 314.93 \\
\hline JP225 & 0.0000056 & 0.0000407 & 0.0000006 & 0.0000000 & 0.0010989 & 19.01 & 453.17 \\
\hline \multicolumn{8}{|c|}{3 months after Lehman Brothers bankruptcy } \\
\hline DE30 & 0.0000315 & 0.0002947 & 0.0000043 & 0.0000000 & 0.0098056 & 23.35 & 643.08 \\
\hline NL25 & 0.0000367 & 0.0003509 & 0.0000046 & 0.0000000 & 0.0106968 & 20.22 & 479.88 \\
\hline FR40 & 0.0000325 & 0.0003055 & 0.0000043 & 0.0000000 & 0.0089419 & 20.38 & 474.38 \\
\hline EU50 & 0.0000311 & 0.0003220 & 0.0000036 & 0.0000000 & 0.0097536 & 23.23 & 610.16 \\
\hline UK100 & 0.0000323 & 0.0003311 & 0.0000037 & 0.0000000 & 0.0091169 & 20.90 & 489.67 \\
\hline AU200 & 0.0000212 & 0.0001779 & 0.0000028 & 0.0000000 & 0.0070321 & 26.44 & 916.44 \\
\hline SPX500 & 0.0000335 & 0.0003448 & 0.0000032 & 0.0000000 & 0.0102949 & 21.23 & 521.89 \\
\hline NAS100 & 0.0000375 & 0.0003963 & 0.0000032 & 0.0000000 & 0.0106116 & 19.37 & 425.04 \\
\hline US2000 & 0.0000439 & 0.0004556 & 0.0000038 & 0.0000000 & 0.0121452 & 19.77 & 441.95 \\
\hline JP225 & 0.0000499 & 0.0006480 & 0.0000032 & 0.0000000 & 0.0264865 & 29.81 & 1079.30 \\
\hline
\end{tabular}


Table 8. Descriptive statistics for equity indexes volatility, Covid-19 crisis

\begin{tabular}{|c|c|c|c|c|c|c|c|}
\hline & Mean & SD & Median & Min & Max & Skew & Kurtosis \\
\hline \multicolumn{8}{|c|}{1 month before Covid-19 recession } \\
\hline DE30 & 0.0000005 & 0.0000032 & 0.0000001 & 0.0000000 & 0.0001042 & 20.38 & 512.25 \\
\hline NL25 & 0.0000005 & 0.0000027 & 0.0000001 & 0.0000000 & 0.0000720 & 18.49 & 412.09 \\
\hline FR40 & 0.0000005 & 0.0000032 & 0.0000001 & 0.0000000 & 0.0001038 & 21.00 & 543.48 \\
\hline EU50 & 0.0000005 & 0.0000028 & 0.0000001 & 0.0000000 & 0.0000805 & 19.85 & 476.43 \\
\hline UK100 & 0.0000005 & 0.0000024 & 0.0000001 & 0.0000000 & 0.0000590 & 16.38 & 316.17 \\
\hline AU200 & 0.0000003 & 0.0000021 & 0.0000001 & 0.0000000 & 0.0000873 & 28.93 & 1098.70 \\
\hline SPX500 & 0.0000004 & 0.0000034 & 0.0000001 & 0.0000000 & 0.0001288 & 26.84 & 880.07 \\
\hline NAS100 & 0.0000008 & 0.0000062 & 0.0000001 & 0.0000000 & 0.0001699 & 22.53 & 565.17 \\
\hline US2000 & 0.0000006 & 0.0000031 & 0.0000001 & 0.0000000 & 0.0001112 & 20.51 & 598.44 \\
\hline JP225 & 0.0000008 & 0.0000077 & 0.0000001 & 0.0000000 & 0.0002872 & 25.51 & 793.18 \\
\hline \multicolumn{8}{|c|}{1 month after Covid-19 recession } \\
\hline DE30 & 0.0000230 & 0.0004082 & 0.0000016 & 0.0000000 & 0.0201744 & 43.22 & 2066.35 \\
\hline NL25 & 0.0000216 & 0.0003760 & 0.0000016 & 0.0000000 & 0.0185459 & 43.19 & 2056.39 \\
\hline FR40 & 0.0000251 & 0.0004905 & 0.0000017 & 0.0000000 & 0.0247962 & 45.53 & 2251.10 \\
\hline EU50 & 0.0000249 & 0.0004399 & 0.0000018 & 0.0000000 & 0.0216999 & 43.14 & 2054.57 \\
\hline UK100 & 0.0000206 & 0.0003946 & 0.0000013 & 0.0000000 & 0.0195066 & 43.51 & 2076.25 \\
\hline AU200 & 0.0000361 & 0.0006563 & 0.0000011 & 0.0000000 & 0.0253576 & 28.61 & 935.94 \\
\hline SPX500 & 0.0000208 & 0.0002720 & 0.0000017 & 0.0000000 & 0.0130813 & 40.40 & 1857.42 \\
\hline NAS100 & 0.0000209 & 0.0002544 & 0.0000021 & 0.0000000 & 0.0123876 & 41.28 & 1939.68 \\
\hline US2000 & 0.0000275 & 0.0003813 & 0.00000 & 0.0000000 & 0.0193766 & 45.75 & 2286.69 \\
\hline JP225 & 0.0000179 & 0.0002886 & 0.0000012 & 0.0000000 & 0.0130253 & 37.35 & 1553.16 \\
\hline \multicolumn{8}{|c|}{3 months before Covid-19 recession } \\
\hline DE30 & 0.0000005 & 0.0000031 & 0.0000001 & 0.0000000 & 0.0001042 & 20.93 & 539.56 \\
\hline NL25 & 0.0000004 & 0.0000023 & 0.0000001 & 0.0000000 & 0.0000720 & 19.91 & 496.52 \\
\hline FR40 & 0.0000005 & 0.0000029 & 0.0000001 & 0.0000000 & 0.0001038 & 21.89 & 599.38 \\
\hline EU50 & 0.0000005 & 0.0000027 & 0.0000001 & 0.0000000 & 0.0000805 & 20.78 & 512.92 \\
\hline UK100 & 0.0000004 & 0.0000020 & 0.0000001 & 0.0000000 & 0.0000590 & 18.64 & 423.99 \\
\hline AU200 & 0.0000003 & 0.0000022 & 0.0000000 & 0.0000000 & 0.0000873 & 27.98 & 997.69 \\
\hline SPX500 & 0.0000003 & 0.0000028 & 0.0000001 & 0.0000000 & 0.0001288 & 29.71 & 1145.15 \\
\hline NAS100 & 0.0000006 & 0.0000052 & 0.0000001 & 0.0000000 & 0.0001699 & 24.98 & 717.41 \\
\hline US2000 & 0.0000005 & 0.0000026 & 0.0000001 & 0.0000000 & 0.0001112 & 21.93 & 737.05 \\
\hline JP225 & 0.0000006 & 0.0000066 & 0.0000000 & 0.0000000 & 0.0002872 & 27.86 & 960.69 \\
\hline \multicolumn{8}{|c|}{3 months after Covid-19 recession } \\
\hline DE30 & 0.0000110 & 0.0002373 & 0.0000010 & 0.0000000 & 0.0201744 & 72.68 & 5973.23 \\
\hline NL25 & 0.0000101 & 0.0002184 & 0.0000009 & 0.0000000 & 0.0185459 & 72.76 & 5961.61 \\
\hline FR40 & 0.0000117 & 0.0002836 & 0.0000011 & 0.0000000 & 0.0247962 & 77.68 & 6646.07 \\
\hline EU50 & 0.0000116 & 0.0002547 & 0.0000011 & 0.0000000 & 0.0216999 & 73.36 & 6037.22 \\
\hline UK100 & 0.0000098 & 0.0002283 & 0.0000008 & 0.0000000 & 0.0195066 & 74.11 & 6115.82 \\
\hline AU200 & 0.0000166 & 0.0003875 & 0.0000007 & 0.0000000 & 0.0253576 & 46.48 & 2553.58 \\
\hline SPX500 & 0.0000107 & 0.0001619 & 0.0000010 & 0.0000000 & 0.0130813 & 63.97 & 4901.50 \\
\hline NAS100 & 0.0000107 & 0.0001527 & 0.0000010 & 0.0000000 & 0.0123876 & 64.12 & 4958.38 \\
\hline US2000 & 0.0000166 & 0.0002310 & 0.0000017 & 0.0000000 & 0.0193766 & 68.98 & 5613.99 \\
\hline JP225 & 0.0000093 & 0.0001788 & 0.0000006 & 0.0000000 & 0.0130253 & 54.39 & 3536.48 \\
\hline
\end{tabular}

